\title{
Mapping Annual Forest Cover by Fusing PALSAR/PALSAR-2 and MODIS NDVI During 2007-2016
}

Yihang Zhang a, Feng Ling ${ }^{a *}$, Giles M. Foody ${ }^{\mathrm{b}}$, Yong Ge ${ }^{\mathrm{c}}$, Doreen S. Boyd ${ }^{\mathrm{b}}$, Xiaodong Li ${ }^{\mathrm{a}, \mathrm{b}}$,

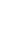

\author{
Yun Du ${ }^{\text {a }}$, Peter M. Atkinson d, c, e, f
}

a. Key Laboratory of Monitoring and Estimate for Environment and Disaster of Hubei Province, Institute of Geodesy and Geophysics, Chinese Academy of Sciences, Wuhan 430077, China;

b. School of Geography, University of Nottingham, NG7 2RD Nottingham, UK;

c. State Key Laboratory of Resources and Environmental Information System, Institute of

Geographic Sciences \& Natural Resources Research, Chinese Academy of Sciences, Beijing

$$
\text { 100101, China; }
$$

d. Lancaster Environment Center, Faculty of Science and Technology, Lancaster University,

$$
\text { Lancaster LA1 4YQ, UK; }
$$

e. School of Geography and Environmental Science, University of Southampton, Highfield,

$$
\text { Southampton SO17 1BJ, UK; }
$$

f. School of Natural and Built Environment, Queen's University, Belfast, Belfast BT7 1NN, UK.

$$
\text { (Corresponding author: lingf@,whigg.ac.cn) }
$$


Abstract: Advanced Land Observing Satellite (ALOS) Phased Arrayed L-band Synthetic Aperture Radar (PALSAR) HH and HV polarization data were used previously to produce annual, global $25 \mathrm{~m}$ forest maps between 2007 and 2010, and the latest global forest maps of 2015 and 2016 were produced by using the ALOS-2 PALSAR-2 data. However, annual $25 \mathrm{~m}$ spatial resolution forest maps during 20112014 are missing because of the gap in operation between ALOS and ALOS-2, preventing the construction of a continuous, fine resolution time-series dataset on the world's forests. In contrast, the MODerate Resolution Imaging Spectroradiometer (MODIS) NDVI images were available globally since 2000. This research developed a novel method to produce annual $25 \mathrm{~m}$ forest maps during 2007-2016 by fusing the fine spatial resolution, but asynchronous PALSAR/PALSAR-2 with coarse spatial resolution, but synchronous MODIS NDVI data, thus, filling the four-year gap in the ALOS and ALOS-2 time-series, as well as enhancing the existing mapping activity. The method was developed concentrating on two key objectives: 1) producing more accurate $25 \mathrm{~m}$ forest maps by integrating PALSAR/PALSAR-2 and MODIS NDVI data during 2007-2010 and 2015-2016; 2) reconstructing annual $25 \mathrm{~m}$ forest maps from time-series MODIS NDVI images during 2011-2014. Specifically, a decision tree classification was developed for forest mapping based on both the PALSAR/PALSAR-2 and MODIS NDVI data, and a new spatial-temporal super-resolution mapping was proposed to reconstruct the $25 \mathrm{~m}$ forest maps from time-series MODIS NDVI images. Three study sites including Paraguay, the USA and Russia were chosen, as they represent the world's three main forest types: tropical forest, temperate broadleaf and mixed forest, and boreal conifer forest, respectively. Compared with traditional methods, the proposed approach produced the most accurate continuous time-series of fine spatial resolution forest maps both visually and quantitatively. For the forest maps during 2007-2010 and 2015-2016, the results had greater overall accuracy values (more than 98\%) than those of the original JAXA forest product. For the 
reconstructed $25 \mathrm{~m}$ forest maps during 2011-2014, the increases in classifications accuracy relative to three benchmark methods were statistically significant, and the overall accuracy values of the three study sites were almost universally greater than $92 \%$. The proposed approach, therefore, has great potential to support the production of annual $25 \mathrm{~m}$ forest maps by fusing PALSAR/PALSAR-2 and MODIS NDVI during 2007-2016. 
Forests store a large amount of terrestrial carbon and provide the natural habitats for almost twothirds of the Earth's biodiversity (Gillespie et al. 2008). Despite their importance, the world's forests are decreasing at a rate of approximately 7 million ha annually (Canadell and Raupach 2008), including significant deforestation in the tropics, because of activities such as fuel-wood collection, agricultural expansion, industrialization and urbanization (Curtis et al. 2018; Foley et al. 2005). Many ecosystem services and climate-related problems, including accelerated soil erosion, biodiversity losses and increasing concentrations of atmospheric greenhouse gases, were enhanced by the loss and degradation of forests (Foley et al. 2005; Pan et al. 2011). Meanwhile, in some parts of the world, for example, due to the reforestation and afforestation supported by East Asian countries (Fang et al. 2001) and improvement of forest conditions in European countries (Kauppi et al. 1992), forest areas in these regions are increasing locally. These new forests have become a substantial sink of atmospheric carbon and contribute to addressing the problems caused by the loss and degradation of forests (Foley et al. 2005). With the threat to the World's forest resources increasing, accurate and timely monitoring of forest cover change, including both decreases and increases, is needed urgently (Curtis et al. 2018; Sexton et al. 2016). remote sensing has become an effective tool for monitoring the Earth's forest resources. At a regional scale, a variety of remote sensing datasets have been applied to produce forest maps. For example, Achard and Estreguil (1995) applied the Advanced Very High Resolution Radiometer (AVHRR) to map forest cover across Southeast Asia. Morton et al. (2005) applied MODerate resolution Imaging 
integrated both MODIS and Landsat data to monitor forest cover change in the Congo Basin. Pekkarinen et al. (2009) applied Landsat Enhanced Thematic Mapper plus (ETM+) data to produce Pan-European forest maps. Dong et al. (2012) applied a range of datasets, including the Phased Array type L-band Synthetic Aperture Radar (PALSAR), MEdium Resolution Imaging Spectrometer (MERIS), and MODIS together with Forest Resources Assessments (FRA), to produce forest maps of Mainland Southeast Asia. However, given the rapidly expanding number of available remote sensing satellite sensor datasets, it is of great interest to consider how to provide time-series "wall-to-wall" forest maps, which have a fine spatial resolution (FR) and are updated at a high temporal frequency, to monitor the world's forest cover and its dynamics at the global scale (Motohka et al. 2014).

With the inherent benefits of spatial and temporal consistency, satellite-derived forest cover and change mapping at the global scale is currently a research priority. Generally, forest cover can be obtained from satellite-derived global land cover datasets, such as the $1 \mathrm{~km}$ Global Land Cover (GLC2000) dataset (Bartholome and Belward 2005) for 2000, the $1 \mathrm{~km}$ Global Land Cover dataset provided by National Mapping Organizations (GLCNMO) for 2003 (Tateishi et al. 2011), the $300 \mathrm{~m}$ Global Land Cover Product (GlobCover) for 2005, 2006 and 2009 (Bicheron et al. 2011), the $500 \mathrm{~m}$ annual MODIS Global Land Cover type product (MCD12Q1) (Friedl et al. 2002) and the latest $30 \mathrm{~m}$ Finer Resolution Observation and Monitoring-Global Land Cover product (FROM-GLC) (Gong et al. 2013). But these satellite-derived global land cover products do not focus exclusively on forest cover and, thus, cannot assure the accuracy of forest cover mapping (Kaptué Tchuenté et al. 2011).

Fortunately, various satellite-derived products focusing on global forest cover have been developed. The first is annually MODIS Vegetation Continuous Field (VCF) product, which was derived from the images of MODIS carried on the Terra and Aqua satellites since 2000 (DiMiceli et al. 2011; Hansen et 
al. 2003). The MODIS VCF is currently the only product that can provide annual tree canopy cover since 2000, but many tree cover change occurs in patches have smaller spatial size than the MODIS VCF (Jin and Sader 2005a). Subsequently, a global continuous field tree cover product $(30 \mathrm{~m})$ was produced by using the Landsat series data for circa 2000, 2005 and 2010 (Sexton et al. 2013). Compared with the MODIS VCF, Landsat tree cover product has a finer spatial resolution, which supports more accurate forest cover change assessment. However, due to the relatively infrequent revisit coverage provided by the Landsat data in combination with cloud cover contamination (Townshend et al. 2012), global mosaics were produced only for the years 1975, 1990, 2000, 2005 and 2010 (Hansen et al. 2009). Therefore, it is impossible to produce global wall-to-wall Landsat tree cover maps on an annual basis, and this limits the application of the Landsat tree cover product for long-term observation and monitoring of global forest cover change. More recently, a global $30 \mathrm{~m}$ forest cover change product was published during 2000-2012 (Hansen et al. 2013). This latest product provided global forest loss per year during 2000-to-2017 through the application of a statistical sampling approach, but the forest gain was provided for 2012 only and limited to a specific inter-annual period. It is noteworthy that information on forest gain is crucial for some studies, but forest cover gain maps cannot be provided on an annual basis for this product (Hansen et al. 2013).

The Japan Aerospace Exploration Agency (JAXA) launched the Advanced Land Observing Satellite (ALOS) with the PALSAR in January 2006, and it provided annual global time-series cloud-free PALSAR data covering all the world's forests during 2007-to-2010. Numerous studies have demonstrated that the low-frequency L-band Synthetic Aperture Radar (SAR) $(24 \mathrm{~cm})$ is more sensitive to forest characteristics than other widely used SAR bands (Rosenqvist et al. 2000; Shimada and Isoguchi 2002). With the global ALOS PALSAR mosaics, a new global, annual, wall-to-wall forest map product 
from 2007 to 2010 with a spatial resolution of $25 \mathrm{~m}$, was obtained using a threshold method. Forest in this product is defined as natural forest patches with the area larger than 0.5 ha and tree canopy cover over 10\% (Shimada et al. 2014), mirroring the Food and Agriculture Organization (FAO) definition (FAO 2010). The ALOS PALSAR forest map products provided the first global annual $25 \mathrm{~m}$ fine spatial resolution forest cover mapping, and are useful for investigating forest cover change, the terrestrial origin of carbon emissions, and promoting the activity of the Reducing Emissions from Deforestation and forest Degradation Plus (REDD+) programme. However, the ALOS PALSAR data acquisition ended in April 2011 because of a power failure suffered by the satellite. Thus, forest map products were produced only for the four years: 2007, 2008, 2009 and 2010. Fortunately, the ALOS-2 satellite was launched successfully in May 2014. As an upgrade of ALOS PALSAR, the PALSAR-2 sensor aboard ALOS-2 started to provide global PALSAR-2 data since 2015. However, because of the gap between the demise of ALOS-1 and the launch time of ALOS-2, the annual ALOS PALSAR datasets between 2011 and 2014 inclusive do not exist. Therefore, annual ALOS PALSAR forest maps are missing during 2011-to-2014. To provide a long-term, annual, $25 \mathrm{~m}$ forest map product, there is a desire to reconstruct the ALOS PALSAR forest maps during 2011-2014. Since there is no ALOS PALSAR or ALOS-2 PALSAR-2 dataset during this period, alternative remote sensing satellite sensor datasets need to be utilized during 2011-to-2014. With a large number of freely available satellite sensor datasets available, it is possible to provide remote sensing datasets at different spatial resolutions during 2011-2014. However, to be suitable, the remote sensing dataset should satisfy a key criterion; that is, the dataset should be collected at the global scale and be capable of showing the annual change. The Landsat series datasets, including Thematic Mapper (TM, Landsat 5), Enhanced Thematic Mapper Plus (ETM+, Landsat 7) and Operational Land Imager (OLI, Landsat 8), can be acquired free from the USGS since 2008 (Woodcock 
et al. 2008), and are a reasonable choice. However, the relatively infrequent revisit interval makes it challenging to assemble annual Landsat dataset mosaics at the global scale during 2011-2014. Moreover, there are almost no available Landsat TM or OLI images in 2012, since Landsat 5 was out of operation in November 2011 and Landsat 8 was launched in February 2013. Other optical remote sensing satellite sensor datasets, such as from sensors carried by the SPOT and Advanced Spaceborne Thermal Emission and Reflection Radiometer (ASTER), have similar problems as those of the Landsat satellites. Although the Radarsat-2 system can provide cloud-free FR SAR mosaics at the global scale with an interval of one year for forest mapping (Evans et al. 2010; Maghsoudi et al. 2013), it is not free, which could make the cost of utilization of Radarsat-2 datasets prohibitive.

In contrast to the fine spatial resolution systems, the moderate spatial resolution remote sensing satellite systems, such as MODIS and MERIS, are more suitable, as they are freely available at the global scale and have a daily revisit capability and wide swath width. Since the ENVISAT satellite lost contact with Earth in April 2012, the MERIS sensor it carried has not been providing data since then. Fortunately, MODIS can produce a global, timely, wall-to-wall dataset at spatial resolutions of $250 \mathrm{~m}$ and $500 \mathrm{~m}$ with less than one-year intervals from 2000 to the present day (Giri et al. 2005). Motivated by this situation, this research aimed to use the MODIS images as the data source to reconstruct the missing PALSAR forest maps during 2011-2014, so as to provide an uninterrupted time-series of annual FR forest maps from 2007-to-2016. Specifically, the $250 \mathrm{~m}$ time-series MODIS NDVI product was chosen, because it contains much phenological information about the spatio-temporal features of different forest types around the world. Moreover, MODIS NDVI images have been previously used together with PALSAR datasets to increase the forest cover mapping accuracy in monsoonal Asia in 2010 (Qin et al. 2016) and South America during 2007-2010 (Qin et al. 2017). 
and consequently, MODIS images are often dominated by mixed pixels in spatially heterogeneous areas

(Keshava and Mustard 2002). Spectral unmixing methods are commonly applied to MODIS NDVI data

to estimate fractional forest cover (Beck et al. 2006; Xiao and Moody 2005). Compared with traditional

pixel-based classification schemes, fractional forest cover is able to depict areas of heterogeneous land

cover and estimates the percentage of each land cover within each pixel (Keshava and Mustard 2002).

Although spectral unmixing method extracts sub-pixel information from the mixed pixels of MODIS

NDVI, the outputs are limited to the percentage values and have the same spatial resolution as the input.

for different land cover class fractions obtained from spectral unmixing (Atkinson 1997; Foody 1998).

In this context, the fractional forest map can be used for the SRM model to generate FR forest maps.

NDVI images during 2011-2014. In the present case, using only the input of coarse spatial resolution

Su et al. 2012), Hopfield neural network (Muad and Foody 2012; Tatem et al. 2002), Markov random 
CR proportion images at the time of prediction and FR land cover map at a previous time, a sub-pixel land cover change mapping (SLCCM) method was proposed by Ling et al. (2011). Subsequently, Wang et al. (2015) proposed a fast sub-pixel change detection approach, Li et al. (2014b) proposed a Hopfield neural network spatial-temporal SRM approach, Wu et al. (2017) proposed a back-propagation neural network spatial-temporal SLCCM method, and Xu et al. (2017) proposed a sparse representation subpixel change detection method. In terms of land cover applications, Li et al. (2017) proposed a novel fusion model to generate time-series of FR land cover maps, Li et al. (2014a) used 500 m MODIS reflectance images to generate FR forest maps by developing a Markov Random Field based spatialtemporal SRM approach, and Zhang et al. (2017a) produced FR time-series forest maps from multiscale MODIS images by proposing a learning-based spatial-temporal SRM method.

It is noteworthy that the existing 25 m PALSAR/PALSAR-2 forest maps during 2007-2010 and 2015-2016 contain much forest cover spatial pattern information. Abovementioned spatial-temporal SRM methods are, therefore, expected to reconstruct the missing PALSAR forest maps during 20112014 from MODIS NDVI images by integrating the prior information in existing $25 \mathrm{~m}$ PALSAR/PALSAR-2 forest maps. However, current, state-of-the-art, spatial-temporal SRM models are developed based on one (previous) or two (previous and later) FR land cover maps. In fact, all of the PALSAR/PALSAR-2 forest maps during 2007-2010 and 2015-2016 contain useful prior information, which may benefit the reconstructed forest maps during 2011-2014. Motivated by this, a novel spatialtemporal SRM model is developed to reconstruct the ALOS PALSAR forest maps during 2011-2014 from MODIS NDVI images by taking advantage of all the PALSAR/PALSAR-2 forest maps during 2007-2010 and 2015-2016. Moreover, to further improve the accuracy of forest mapping from existing PALSAR/PALSAR-2 data, a decision tree algorithm was used to produce new PALSAR/PALSAR-2 

during 2007-2010 and 2015-2016, but also improve the reconstructed FR forest maps during 2011-2014, as the new FR forest maps during 2007-2010 and 2015-2016 are the input of the new spatial-temporal SRM method.

PALSAR/PALSAR-2 and MODIS NDVI data during 2007-2010 and 2015-2016; (b) estimate $250 \mathrm{~m}$

210 forest and non-forest fraction (FNF) maps during 2011-2014 from annual time-series MODIS NDVI

211 images with kernel ridge regression (KRR); (c) develop a new spatial-temporal SRM model that is based on all the existing FR forest maps during 2007-2010 and 2015-2016, and apply it to reconstruct FR forest maps for 2011-2014; (d) produce annual FR forest cover change maps (forest cover increase and decrease)

214 during 2007-2016 for the selected study sites. 


\section{Study area and data}

216

\subsection{Study area}

To validate the performance of the proposed approach for the world's various forests, three study sites located in Paraguay, USA and Russia were selected, as they represent examples of the Earth's three main forest types: tropical forest, temperate broadleaf and mixed forest and boreal forest, respectively. The locations of the three study sites and the corresponding ALOS PALSAR images (RGB: HH, HV and HH-HV) for 2010 are shown in Fig. 1.

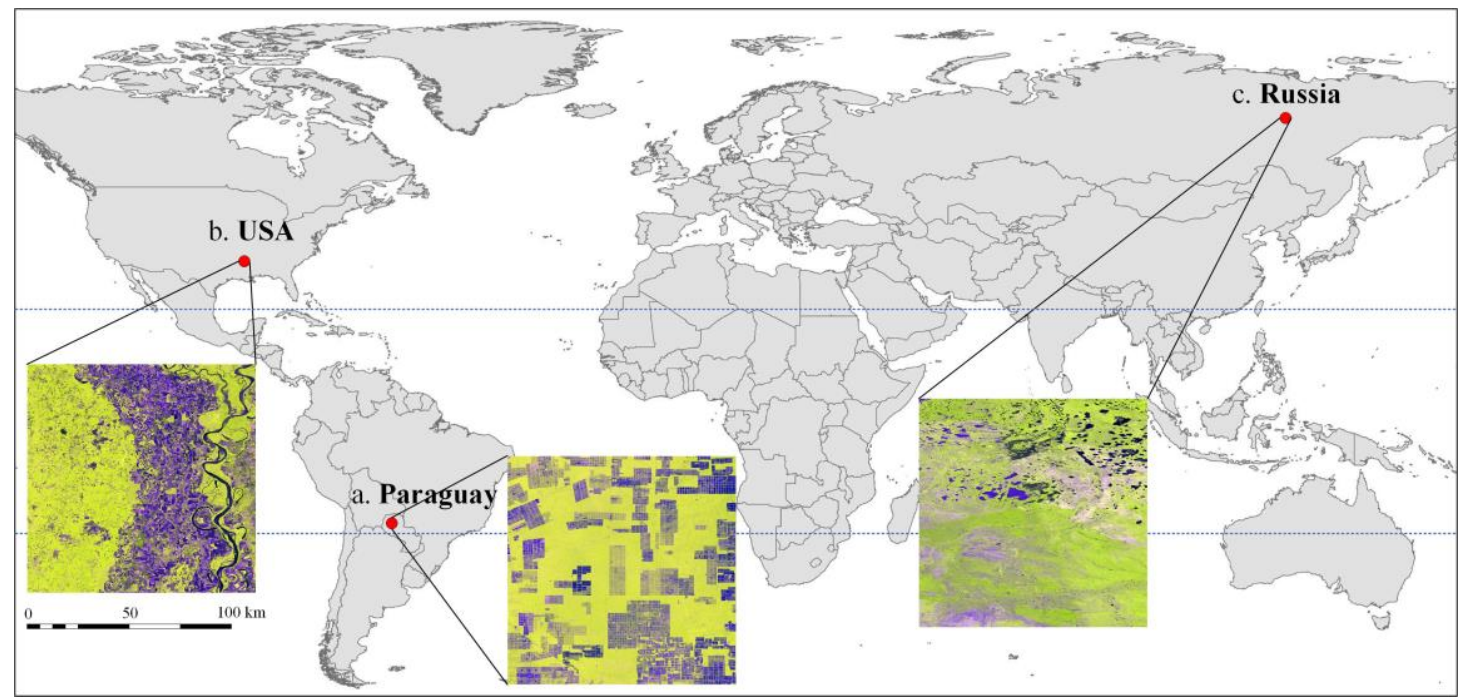

Fig. 1. Geolocations of the three study sites in this research. (a) Paraguay tropical forest; (b) USA temperate broadleaf and mixed forest; (c) Russia boreal forest.

Paraguay is situated on the northern part of the plain of La Plata, and the Paraguay river divides it from north to south into two parts. The eastern side of the Paraguay river comprises hills, marshes, and plains. It accounts for about one-third of the territory and more than $90 \%$ of the country's populations. The western side of the Paraguay river, referred to Chaco area, is mostly covered by grasslands and tropical dry forests. The study area in Paraguay was at the province of Boquerón, which is in the northwest of the Chaco area. During the past few decades, serious deforestation of tropical dry forest occurred in the Chaco woodlands of Paraguay (Hansen et al. 2013). 

temperate broadleaf and mixed forests. It is noted that there are almost no natural forests in the southeastern USA, as the forests in this area are often associated with extensive forestry land use (Hansen et al. 2013; Olson et al. 2001). Short-cycle tree planting and harvesting which may result in forest increase or decrease is customary for the forest covers in southeastern Arkansas.

As most regions of Siberia belong to the cold climate of sub-arctic coniferous forests, vegetation in Siberia, Russia is covered mainly by the tundra, forest swamps, Taiga coniferous forests, and forest grasslands. The study site in Russia was selected in the west of the Yakutsk city of Russia, which is in the center of Siberia and is covered by boreal forests. Due to frequent forest fires, this region has experienced significant forest loss of boreal forests, which contribute greatly to global carbon emissions (Alexander et al. 2014).

\subsection{Datasets and preprocessing} $250 \mathrm{~m}$ MODIS NDVI product of MOD13Q1, and it was collected from the NASA Earthdata search are listed in Table 1. For each of the study sites, there are four scenes of ALOS PALSAR images during 2007-2010, two scenes of ALOS-2 PALSAR-2 images during 2015-2016, and 230 scenes of MOD13Q1 images during 2007-2016 (23 scenes per year). More information about these datasets and the preprocessing are reported in the following sections. 


\begin{tabular}{|c|c|c|c|c|c|}
\hline Dataset & Spatial resolution $(\mathrm{m})$ & Area $\left(\mathrm{km}^{2}\right)$ & Track number & Years & Number \\
\hline \multirow{3}{*}{ ALOS PALSAR } & \multirow{3}{*}{25} & \multirow{3}{*}{$112.5 \times 112.5$} & S21W061(Paraguay) & \multirow{3}{*}{$2007-2010$} & \multirow{3}{*}{12} \\
\hline & & & N34W092(USA) & & \\
\hline & & & N64E126(Russia) & & \\
\hline \multirow{3}{*}{$\begin{array}{c}\text { ALOS-2 PALSAR- } \\
2\end{array}$} & \multirow{3}{*}{25} & \multirow{3}{*}{$112.5 \times 112.5$} & S21W061(Paraguay) & \multirow{3}{*}{ 2015-2016 } & \multirow{3}{*}{6} \\
\hline & & & N34W092(USA) & & \\
\hline & & & N64E126(Russia) & & \\
\hline \multirow{3}{*}{ MOD13Q1 } & \multirow{3}{*}{250} & \multirow{3}{*}{$1200 \times 1200$} & h12v11(Paraguay) & & \multirow{3}{*}{690} \\
\hline & & & h10v05(USA) & $2007-2016$ & \\
\hline & & & h23v02(Russia) & & \\
\hline
\end{tabular}

\subsubsection{5 m ALOS PALSAR and ALOS-2 PALSAR-2}

JAXA launched the ALOS satellite on Jan. 24, 2006 and it operated until April 2011, but then stopped working because of a power failure, while the ALOS-2 was launched on May 24, 2014. At the beginning of 2014, JAXA started to release the annual global $25 \mathrm{~m}$ ALOS PALSAR mosaic for 20072010 and ALOS-2 PALSAR-2 mosaic since 2015, and it also provided annual global $25 \mathrm{~m}$ FNF maps during 2007-2010 and 2015-2017 by classifying the backscattering intensity values in

PALSAR/PALSAR-2 mosaics (http://www.eorc.jaxa.jp/ALOS/en/palsar_fnf/fnf index.htm, where the mosaics were tiled into $1^{\circ} \times 1^{\circ}$ areas of $4500 \times 4500$ pixels). Fine Beam Dual (FBD) modes of PALSAR and PALSAR-2 are based on the dual polarizations of horizontally transmitted and horizontally (HH) and horizontally transmitted and vertically (HV). For both PALSAR and PALSAR-2, the digital number values of original $\mathrm{HH}$ and $\mathrm{HV}$ polarizations were converted into the normalized gamma-naught radar backscattering coefficients $\gamma^{o}$ (unit: decibel, $d B$ ). Let $C$ be the absolute calibration factor of -83 . The conversion process is expressed as (Rosenqvist et al. 2007):

$$
\gamma^{o}(d B)=10 \times \log _{10} \mathrm{DN}^{2}+C
$$

It is well known that "salt and pepper" noise is generally contained in the PALSAR/PALSAR-2 
Acton 2002), was, therefore, applied to the HH and HV images, so as to reduce "salt and pepper" noise, where the spatial size of the adaptive Enhanced Lee filter was $5 \times 5$ pixels. In addition to the $\mathrm{HH}$ and $\mathrm{HV}$, the difference and ratio values between them are also used for forest mapping. Therefore, there were four layers, including $\mathrm{HH}, \mathrm{HV}, \mathrm{HH}-\mathrm{HV}$ and $\mathrm{HH} / \mathrm{HV}$, in the merged SAR images. From the false color map of PALSAR (RGB: HH, HV, and HH-HV) shown in Fig. 2, it is evident that forest cover in all of the study sites is distinguished from other land covers, such as soil, water and vegetation.

\subsubsection{Time-series MODIS NDVI}

The MODIS/Terra Vegetation Indices 16-Day L3 Global 250 m composite product (version V006) of MOD13Q1 was employed in this research, where each value of MOD13Q1 indicates the best quality pixel value within the observed 16-days period. The NDVI was selected from the two available vegetation indices (EVI and NDVI) in the MOD13Q1 product. For each year, there are 23 scenes of MOD13Q1 NDVI images, but it is difficult to ensure that all of the pixels within the NDVI time-series are of good quality because of the clouds, atmospheric changes, and satellite system errors. To reduce singular pixels in the MOD13Q1 NDVI images and reconstruct the long-term change trend of vegetation, the Savitzky-Golay filter (Chen et al. 2004) was applied to the annual time-series NDVI images. As shown in the third column of Fig. 2, the mean NDVI curves, after application of the Savitzky-Golay filter, of forest covers in the three study sites are continuous and smooth and, thus, have great potential to characterize the spatio-temporal features of the three different forest types. The annual maximum NDVI images (termed as MODIS NDVImax) were calculated from the 23 scenes of 16-days MOD13Q1 NDVI images of each year, and they can be integrated with the PALSAR/PALSAR-2 images of the years of 2007-2010 and 2015-2016 to increase the classification accuracy of the forest maps (Qin et al. 2017). 

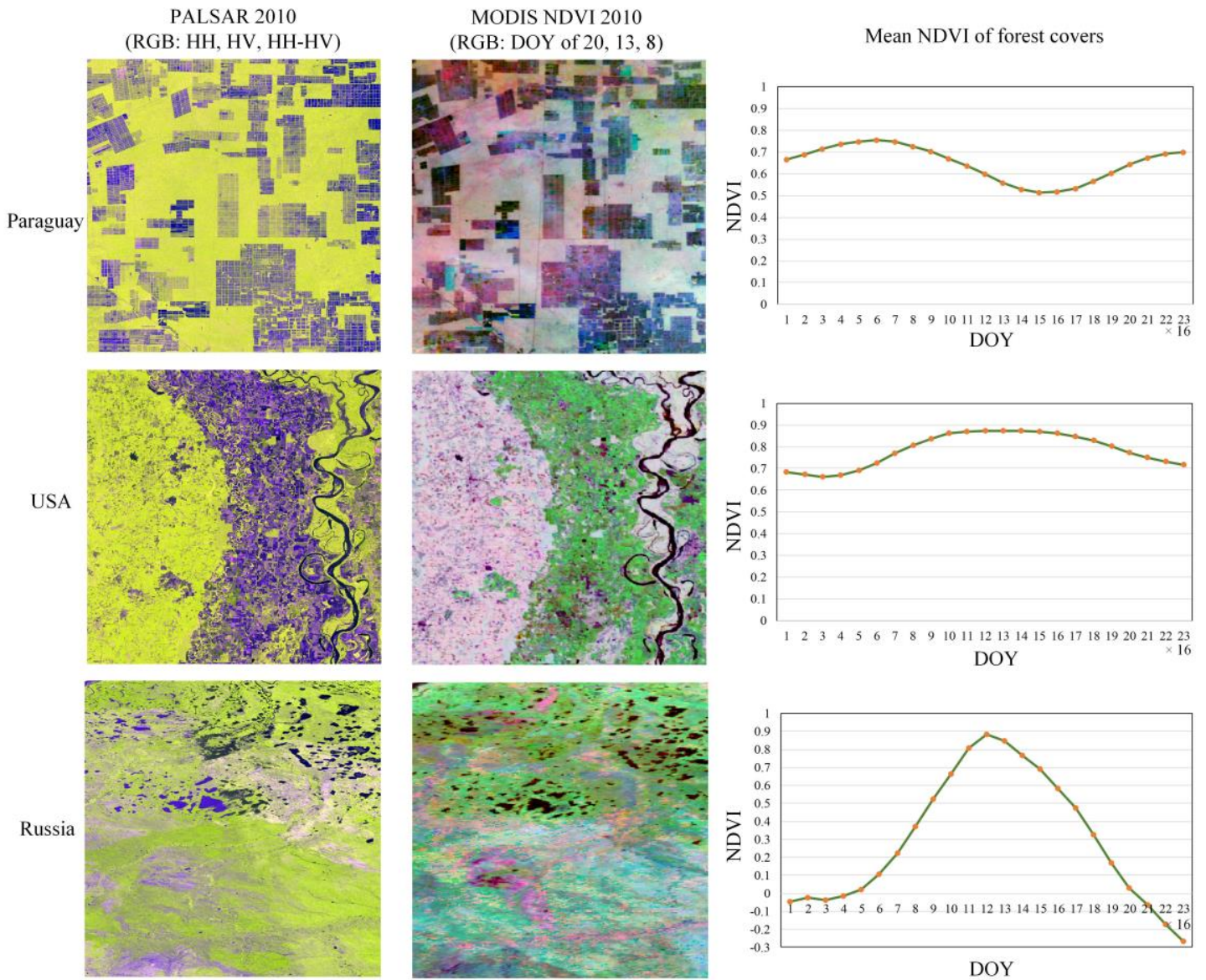

Fig. 2. PLASAR, MODIS NDVI images and time-series NDVI curves of forest cover at the year of 2010 for three study areas. 
By fusing the time-series PALSAR/PALSAR-2 and MODIS NDVI data, the proposed approach

297 aims to produce annual $25 \mathrm{~m}$ forest maps during 2007-2016. It is noteworthy that this research follows

the same definition of forest cover as used in the JAXA PALSAR/PALSAR-2 FNF maps, where tree

forest maps during 2007-2016 consistent with the adopted definition of "forest cover".

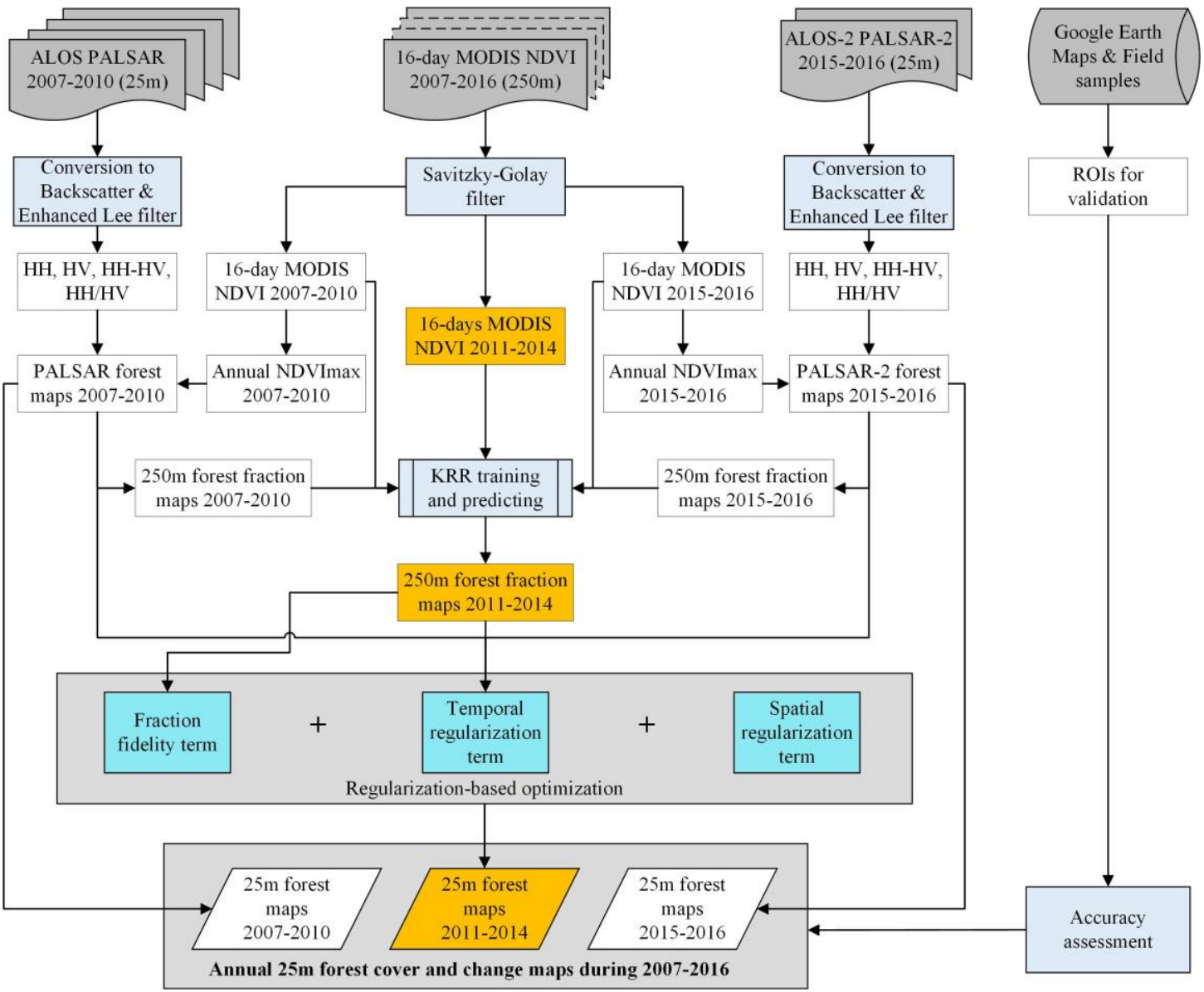



method.

\subsection{Forest mapping by integrating PALSAR/PALSAR-2 and MODIS NDVI}

JAXA released annual global $25 \mathrm{~m}$ forest maps during 2007-2010 and 2015-2017 by classifying the

PALSAR/PALSAR-2 mosaic. However, since PALSAR/PALSAR-2 cannot provide phenological

information about the forests, many other land covers (such as bare rock and bush) which have similar

backscattering characteristics as those of forest may be misclassified as forest. To solve this issue, some

studies integrated PALSAR/PALSAR-2 and MODIS NDVImax to produce more accurate forest maps

(Dong et al. 2012; Qin et al. 2016; Qin et al. 2017; Sheldon et al. 2012). Therefore, a decision tree

algorithm based on the PALSAR/PALSAR-2 and MODIS NDVI images was implemented to map forests.

Table 2. Threshold values of the PALSAR and PALSAR-2 merged images to map forest cover for the three study sites.

\begin{tabular}{|c|c|c|c|c|c|c|}
\hline & & $\mathrm{HV}$ & $\mathrm{HH}$ & HH-HV & $\mathrm{HH} / \mathrm{HV}$ & $\begin{array}{c}\text { MODIS } \\
\text { NDVI }\end{array}$ \\
\hline \multirow{2}{*}{ Paraguay } & PALSAR & $-11.52 \sim-15.59$ & $-5.68 \sim-10.50$ & $2.51 \sim 7.52$ & $0.45 \sim 0.80$ & $0.55 \sim 1.0$ \\
\hline & PALSAR-2 & $-9.74 \sim-15.75$ & $-2.98 \sim-11.05$ & $2.51 \sim 9.62$ & $0.34 \sim 0.81$ & $0.55 \sim 1.0$ \\
\hline \multirow{2}{*}{ Russia } & PALSAR & $-9.62 \sim-16.17$ & $-3.83 \sim-10.92$ & $3.35 \sim 8.4$ & $0.34 \sim 0.71$ & $0.76 \sim 1.0$ \\
\hline & PALSAR-2 & $-10.21 \sim-19.13$ & $-4.56 \sim-10.85$ & $3.13 \sim 9.37$ & $0.38 \sim 0.76$ & $0.76 \sim 1.0$ \\
\hline \multirow{2}{*}{ USA } & PALSAR & $-8.15 \sim-13.36$ & $-2.79 \sim-8.24$ & $1.46 \sim 8.73$ & $0.27 \sim 0.82$ & $0.72 \sim 1.0$ \\
\hline & PALSAR-2 & $-7.90 \sim-14.11$ & $-2.86 \sim-9.60$ & $0.93 \sim 8.49$ & $0.32 \sim 0.90$ & $0.72 \sim 1.0$ \\
\hline
\end{tabular}

As forests in the three study sites have different structural properties, threshold values were 
existed between ALOS PALSAR and ALOS-2 PALSAR-2, threshold values were also calculated individually for the PALSAR and PALSAR-2 merged images. By contrast, as annual HH and HV backscatter values for PALSAR during 2007-2010 were relatively stable through time (Qin et al. 2017), threshold values used to distinguish forests for each of the study sites were held constant and calculated by using the ROIs for forests, which were collected from the Google Earth high resolution images. For the collection of forest ROIs, it is based on the definition of "forest cover" by FAO (FAO 2010). The same operation was also applied to PALSAR-2 HH and HV backscatters during 2015-2016. Table 2 reports the threshold values of PALSAR and PALSAR-2 merged images with regard to the three study sites, and then the $25 \mathrm{~m}$ forest maps during 2007-2010 and 2015-2016 were produced based on the threshold values.

\subsection{Estimating forest fraction maps from time-series MODIS NDVI with KRR}

Since the world's forests vary greatly, even within a single region, it is difficult to distinguish diverse forest types with only one satellite sensor image. Time-series MODIS NDVI contains significant phenological information about the growth of various vegetation types and has been used widely to identify crops (Wardlow and Egbert 2008), grasslands (Gu et al. 2007) and forests (Jin and Sader 2005b). Here, annual time-series MODIS NDVI data (23 scenes per year) were applied to produce forest fraction maps during 2010-2014 for the distinct forests established at the three study sites.

Instead of directly generating forest fraction maps from the annual MODIS NDVI images by temporal linear mixture analysis of the NDVI profile (Xiao and Moody 2005), a nonlinear method based on KRR was used. Nonlinear methods based on machine learning approaches such as support vector regression, backpropagation neural network and KRR (Bioucas-Dias et al. 2012), have been used widely 


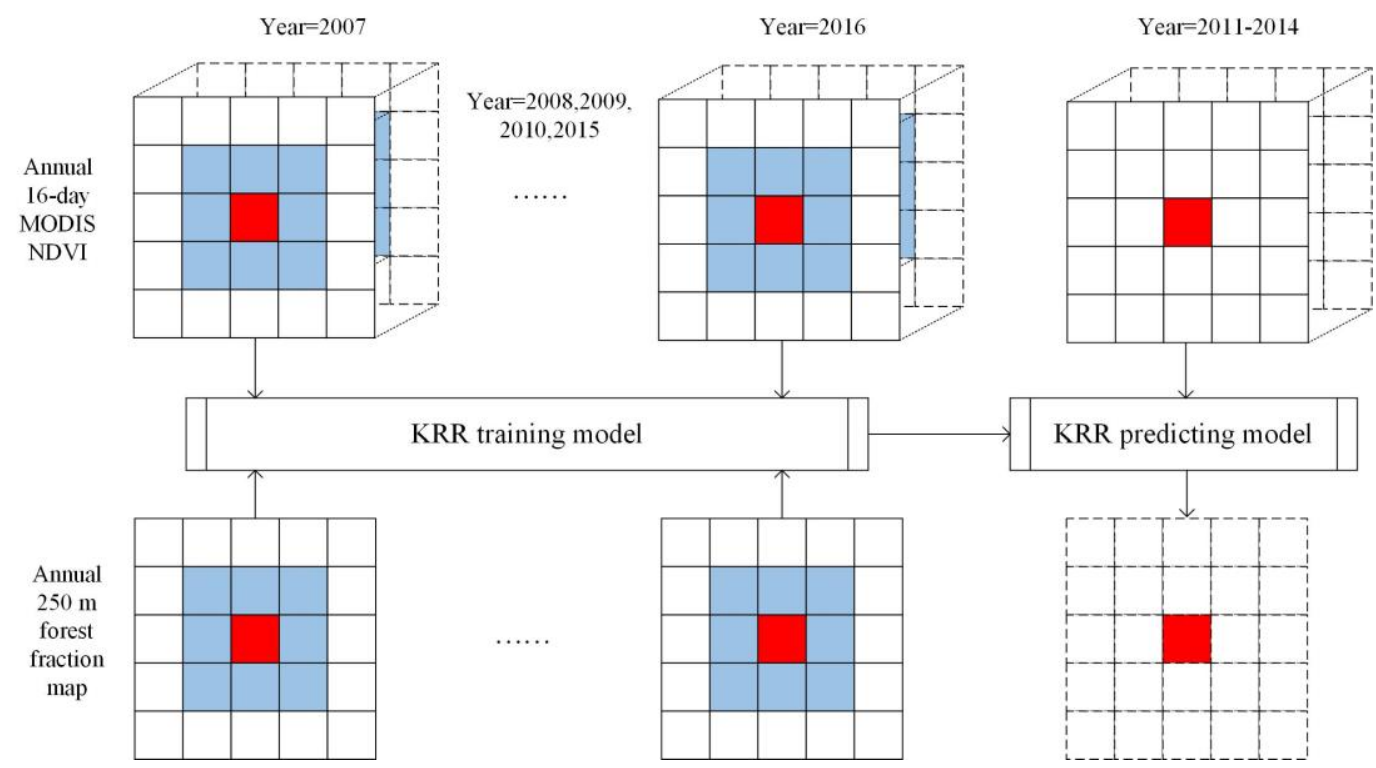

Fig. 4. The process of estimating forest fraction maps from time-series MODIS NDVI by using KRR.

Fig. 4 shows the process of estimating forest fraction maps from time-series MODIS NDVI with KRR. First, existing 25 m forest maps during 2007-2010 and 2015-2016 were averaged spatially to produce annual $250 \mathrm{~m}$ forest fraction maps. The generated $250 \mathrm{~m}$ forest fraction maps and corresponding annual time-series MODIS NDVI images during 2007-2010 and 2015-2016 were then used as the training dataset for the KRR training model. As the performance of the KRR model may be seriously impacted if the size of elements in the training dataset is too numerous (Kim and Kwon 2010), the estimation of forest fraction maps with KRR was completed pixel-by-pixel. As shown in Fig. 4, given a target pixel (red pixel) in the time-series MODIS NDVI images (at any year during 2010-2014), a vector that is composed of 23 NDVI values was used as the input to the KRR predicting model. With the same 
location of the target pixel, six vectors can be extracted from the MODIS NDVI images and six corresponding forest fraction values can be extracted from the forest fraction maps during 2007-2010 and 2015-2016, where the MODIS NDVI values are the input and the forest fraction values are the output of the KRR training model. However, these six vector pairs (one vector pair is composed of 23 NDVI values and one corresponding forest fraction value) are inadequate for the KRR training model. To appropriately increase the size of training dataset, vectors based on the pixels (blue pixels in Fig. 4) that are around the target pixel were also used in the training dataset. Assume the width of the pixel window was 3 , there will be $3 \times 3 \times 6=54$ vector pairs in each training dataset. Once the training model was completed, it was combined with the KRR predicting model to estimate the forest fraction value of the target pixel. The whole forest fraction maps during 2007-2010 and 2015-2016 were estimated pixel-bypixel and year-by-year. After the forest fraction map was estimated, the non-forest fraction map was produced automatically since the sum of the forest and non-forest fraction values per pixel is one.

The training data (see Fig. 4) used in this section are $250 \mathrm{~m}$ forest fraction maps which were produced by averaged spatially from the existing $25 \mathrm{~m}$ forest maps during 2007-2010 and 2015-2016 in section 3.1. As mentioned above, the generation of $25 \mathrm{~m}$ forest maps during 2007-2010 and 2015-2016 was based on the collection of ROIs of forest defined as "tree covered land with an area larger than 0.5 ha, tree height over $5 \mathrm{~m}$ and canopy cover over $10 \%$ ". Therefore, the definition of "forest cover" in the training data is consistent with that of the existing $25 \mathrm{~m}$ forest maps during 2007-2010 and 2015-2016.

\subsection{Reconstructing FR forest maps with a new spatial-temporal SRM method}

\footnotetext{
Let $A\left(t_{p}\right)$ be the $25 \mathrm{~m}$ forest map at the predicting time $t_{p}$, with the aim of the proposed spatial-
} temporal SRM method being to reconstruct it. Assume that $250 \mathrm{~m} \mathrm{FNF}$ fraction maps $F\left(t_{p}\right)$ at the 
prediction time have been produced with the above KRR algorithm, and $A\left(t_{i}\right)$ is the existing $25 \mathrm{~m}$ forest map at time $\boldsymbol{t}_{\boldsymbol{i}} \cdot z$ is the spatial ratio (scale) between the PALSAR/PALSAR-2 and MODIS images pixels, such that the FR forest map contains $\left(M_{1} \times z\right) \times\left(M_{2} \times z\right)$ fine pixels. To provide a solution of $\hat{A}\left(t_{p}\right)$, a regularization-based framework (Kim and Kwon 2010) was used, and it is formulated as follows

$$
\hat{A}\left(t_{p}\right)=\arg \min _{X}\left\{D\left(A\left(t_{p}\right), F\left(t_{p}\right), H\right)-\lambda R^{s m}\left(A\left(t_{p}\right)\right)-\eta R^{s t}\left(A\left(t_{p}\right) \& A\left(t_{i}\right)\right)\right\}
$$

where $D\left(A\left(t_{p}\right), F\left(t_{p}\right), H\right)$ is the data fidelity term, which is applied to build the relationship between the reconstructed $A\left(t_{p}\right)$ to the input FNF fraction maps $F\left(t_{p}\right)$, and $H$ indicates an operation of downsampling. $R^{s m}\left(A\left(t_{p}\right)\right)$ is defined as the spatial smoothing regularization term used to make the results spatially smooth (Ling et al. 2014), while $R^{s t}\left(A\left(t_{p}\right) \& A\left(t_{i}\right)\right)$ is the spatial-temporal regularization term used to incorporate prior information from existing FR forest maps (Ling et al. 2011). $\eta$ and $\lambda$ are two trade-off parameters, and they always used to balance the contribution of different terms. The sections.

\subsubsection{Data fidelity term} estimated $A\left(t_{p}\right)$ consistent with the observed $F\left(t_{p}\right)$. The L2 norm estimator (Atkinson 1997) is used to 
where $H A\left(t_{p}\right)$ indicates the FNF fraction values of the reconstructed FR forest map $A\left(t_{p}\right)$ and is spatially degraded from $A\left(t_{p}\right)$ with a down-sampling operation $H$.

\subsubsection{Spatial smoothness regularization term}

$R^{s m}\left(A\left(t_{p}\right)\right)$ is used as the spatial smoothness regularization term to incorporate sub-pixel scale spatial prior information into the reconstructed forest map $A\left(t_{p}\right)$. For the mature forest, it always tends in the predicted map. In general, the spatial smoothness regularization term is always based on the maximal spatial dependence principle (Atkinson 2005). With this principle, the fine pixel class label in the reconstructed forest map $A\left(t_{p}\right)$ is determined by the land cover classes of neighboring fine pixels, and it is expressed mathematically as

where $K$ is defined as the number of land cover classes (in the present case equal to 2: forest and nonforest). $l$ is the coarse pixel and $v$ denotes a fine pixel within the reconstructed FR forest map. Equation (6) is used to make the fine pixel $v$ equal to the class of forest or non-forest. $O_{v}$ is the symmetric neighborhood of fine pixel $\mathcal{V}$ with a window size of $W$ (contains $W \times W$ fine pixels). $S D_{k}^{l}(v, j)$ is used to measure the spatial dependence for a fine pixel $v$ which is labeled as land 
where $d(v, j)$ indicates the geometric distance calculated between fine pixels $\quad v$ and $j$, and $\varphi$ is

a nonlinear parameter used for the distance decay model.

\subsubsection{Spatial-temporal regularization term}

$$
R^{s t}\left(A\left(t_{p}\right) \& A\left(t_{i}\right)\right) \text { is used as the spatial-temporal regularization term to introduce prior }
$$

information from the existing FR forest maps $A\left(t_{i}\right)$ into the reconstructed FR forest map $A\left(t_{p}\right)$, and it temporal regularization term $R^{s t}\left(A\left(t_{p}\right) \& A\left(\hat{t}_{i}\right)\right)$.

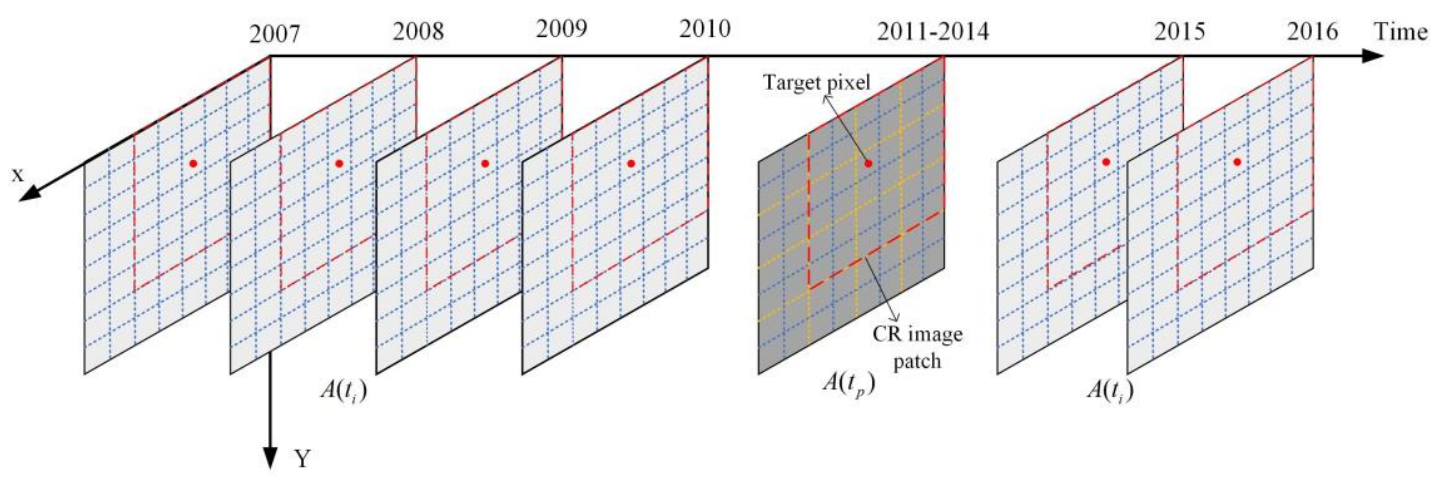

Fig. 5. An indicator of the spatial-temporal dependence model used for the spatial-temporal regularization term.

Because there are only CR FNF fraction maps at the predicting time $t_{p}$, the merging of intermediate FR forest map $A\left(\hat{t}_{i}\right)$ was completed based on the CR fraction maps patch by patch. Let $F\left(t_{i}\right)$ be the $250 \mathrm{~m}$ FNF fraction maps that are spatially averaged from all existing FR forest maps $A\left(t_{i}\right)$ during 2007-2010 and 2015-2016, and $F P\left(t_{p}, l\right)$ and $F P\left(t_{i}, l\right)$ be the CR image patches (including $w$ 

$A P\left(t_{i}, l\right)$ are defined as the FR image patches (including $w \times_{z} \times w \times z$ fine pixels) in $A\left(t_{p}\right)$ and $A\left(t_{i}\right)$, and they are fine image patches of CR image patches $F P\left(t_{p}, l\right)$ and $F P\left(t_{i}, l\right)$, respectively. Let $F P_{d i f}\left(t_{i} t_{p}, l\right)$ be the root-mean-square error (RMSE) of fraction values between $F P\left(t_{p}, l\right)$ and $F P\left(t_{i}, l\right)$, expressed as: with equation (9); the smallest fraction RMSE value was chosen from them. Meanwhile, the corresponding FR image patch of $F P\left(t_{i}, l\right)$ with the smallest $F P_{d i f}\left(t_{i} t_{p}, l\right)$ is regarded as the FR image patch of $A\left(\hat{t}_{i}\right)$. The merged FR forest map $A\left(\hat{t}_{i}\right)$ was then generated from the six existing FR forest maps when all of the CR patches are applied. Therefore, the spatial-temporal temporal term

in which $S D_{k}^{l}\left(v_{i}, j\right)$ is similar to $S D_{k}^{l}(v, j)$ in equations (7) and (8), and is used to measure the spatial image patch within the merged FR forest map $A\left(\hat{t}_{i}\right) . \tau\left(F P\left(t_{p}, l\right), F P\left(\hat{t}_{i}, l\right)\right)$ is expressed as

$$
R^{s t}\left(A\left(t_{p}\right) \& A\left(\hat{t}_{i}\right)\right)=\sum_{l=1}^{M_{1} \times M_{2}} \sum_{v, v_{i}=1}^{z^{2}} \sum_{k=1}^{K} \sum_{j=1}^{O_{v_{i}}} m_{k}^{l}\left(v, v_{i}\right) \cdot S D_{k}^{l}\left(v_{i}, j\right) \cdot \tau\left(F P\left(t_{p}, l\right), F P\left(\hat{t}_{i}, l\right)\right)
$$

dependence between fine pixel $v_{i}$ and neighboring fine pixel $j$ within the symmetric neighborhood $O_{v_{i}}$ (contains $W \times W$ fine pixels). $\tau\left(F P\left(t_{p}, l\right), F P\left(\hat{t}_{i}, l\right)\right)$ is a land cover change indicator used to measure

$$
\tau\left(F P\left(t_{p}, l\right), F P\left(\hat{t}_{i}, l\right)\right)=e^{-6 \cdot F P_{d i f}\left(\hat{t}_{i} t_{p}, l\right)}
$$

where $F P_{d i f}\left(\hat{t}_{i} t_{p}, l\right)$ is the fraction RMSE value between CR image patches $F P\left(t_{p}, l\right)$ and $F P\left(\hat{t}_{i}, l\right)$, 
and it can be calculated with equation (9).

\subsubsection{Model optimization}

The final FR forest map $A\left(t_{p}\right)$ is produced by obtaining the minimum value of the global energy function shown in equation (2). The Iterative Conditional Model (ICM) was used to provide a solution for the model optimization of the spatial-temporal SRM method (Besag 1986), and it was implemented by the following main steps (Zhang et al. 2017a):

1) Initialize the FR forest map $A\left(t_{p}\right)$ with the generated $250 \mathrm{~m}$ FNF fraction maps at the prediction time.

2) Change the class label of the FR forest map, and then calculate the energy values of the data fidelity, spatial smoothness regularization and spatial-temporal regularization terms in equations (3), (4) and (10). Compare the global energy values of the pre- and post-change of class label, and if changing the class label in $A\left(t_{p}\right)$ achieves a smaller global energy value in equation (2), the change is then accepted; otherwise, the change is rejected.

3) Stop the iteration when there are less than $0.1 \%$ of the fine pixels in $A\left(t_{p}\right)$ are changed after two consecutive iterations or the maximal number of iteration is reached; otherwise, return to step (2).

4) When the iteration in step (3) is stopped, the final FR forest map $\hat{A}\left(t_{p}\right)$ was then generated.

\subsection{Accuracy assessment}

Validation was inspired by visual assessment of the maps obtained together with quantitative estimates of classification quality, especially for the forest and non-forest classes. Ground data to support the validation activity were obtained from geo-referenced field photographs, such as from the Global 
Geo-Referenced Field Photo Library, the Global Land Cover Validation Reference Dataset of USGS, and Google Earth high resolution images (Chen et al. 2018; Dong et al. 2014; Qin et al. 2017). Since there were limited geo-referenced field photographs for the three study areas, most ground data were generated from analyses of historical Google Earth images. The collection of reference ground data of forest was based on the forest definition by FAO. In addition, the ground data of non-forest was chosen mostly from the land cover classes of bareland, farmland, and grassland.

Table 3. The number of sample cases for each of the three study sites in each year.

\begin{tabular}{ccccccc}
\hline \multirow{2}{*}{ Year } & \multicolumn{2}{c}{ Paraguay } & \multicolumn{2}{c}{ USA } & \multicolumn{2}{c}{ Russia } \\
\cline { 2 - 7 } & Forest & Non-forest & Forest & Non-forest & Forest & Non-forest \\
\hline 2007 & 434 & 251 & 0 & 0 & 0 & 0 \\
2008 & 362 & 286 & 0 & 0 & 0 & 0 \\
2009 & 362 & 347 & 0 & 0 & 0 & 0 \\
2010 & 369 & 432 & 0 & 0 & 0 & 0 \\
2011 & 445 & 561 & 698 & 540 & 443 & 289 \\
2012 & 453 & 614 & 610 & 546 & 482 & 378 \\
2013 & 489 & 747 & 816 & 494 & 751 & 468 \\
2014 & 503 & 765 & 629 & 524 & 655 & 443 \\
2015 & 542 & 923 & 0 & 0 & 0 & 0 \\
2016 & 549 & 947 & 0 & 0 & 0 & 0 \\
\hline Total & 4508 & 5873 & 2753 & 2104 & 2331 & 1578 \\
\hline
\end{tabular}

The quality and quantity of images in Google Earth varied in time constraining the study but did allow the extraction of a large sample of cases for each class. The approach is not ideal but does provide a basis to acquire ground reference data over the time period studied to evaluate the accuracy with which the sample cases are classed as forest or non-forest. In total 19,147 sample cases were used in the validation activity, and Table 3 indicates the number of cases for each site in each year. The accuracy with which the FNF maps generated labelled the sample cases for the relevant country and year was assessed using standard measures. Specifically, the focus was on overall classification accuracy (OA) and the class-level accuracy expressed as producer's and user's accuracy. 

network (STHNN) (Li et al. 2014b) were used and the accuracy of each approach evaluated.

504 


\subsection{Reproduced FR forest maps during 2007-2010 and 2015-2016}

As the PALSAR/PALSAR-2 data cannot provide phenological information on various forest types,

there is still potential to increase the accuracies of the annual global forest classifications during 2007-

2010 and 2015-2016 published by JAXA. Therefore, a decision tree algorithm based on the integrated

data of annual PALSAR/PALSAR-2 and MODIS NDVImax was applied to reproduce the FR forest maps

of Paraguay during 2007-2010 and 2015-2016. Fig. 6 shows the original PALSAR/PALSAR-2 images
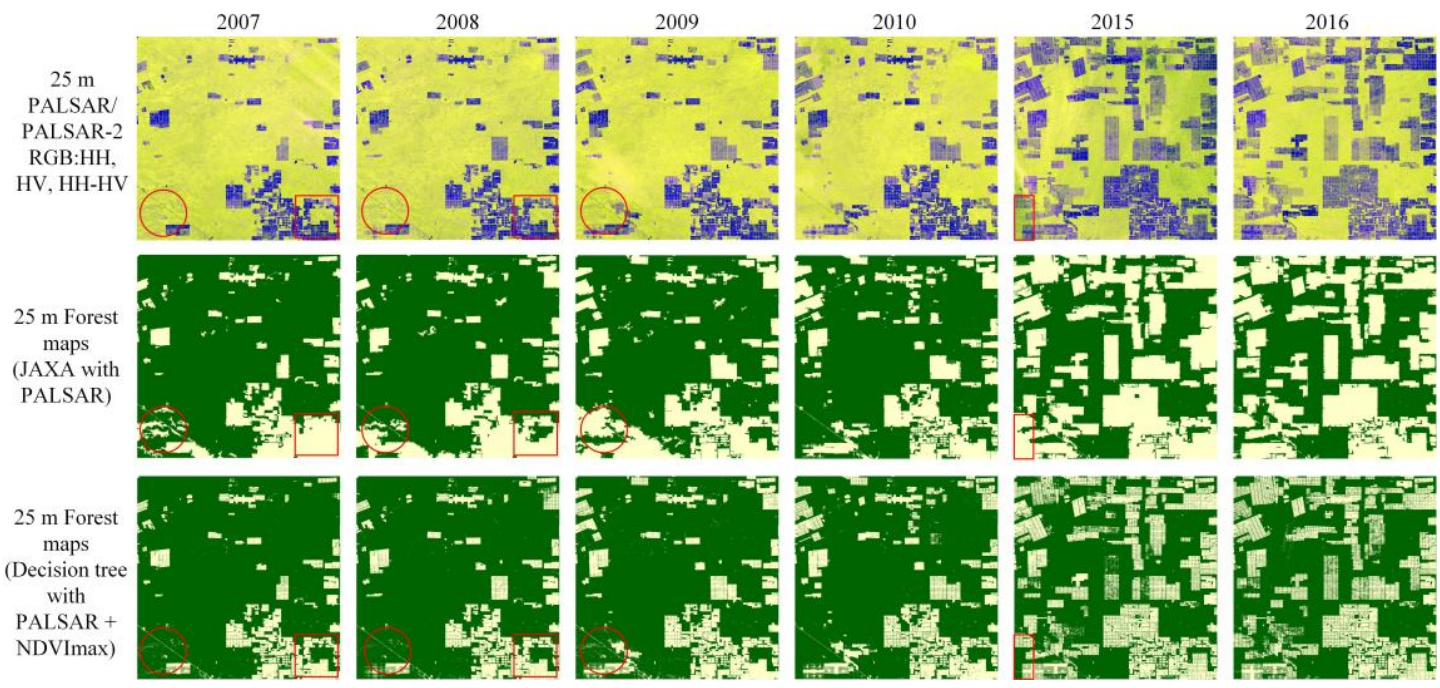

Fig. 6. Paraguay PALSAR/PALSAR-2 RGB images and forest maps produced by JAXA and the proposed approach. 
Table 4. Accuracy values of the Paraguay forest classifications produced by JAXA and the proposed decision tree algorithm.

\begin{tabular}{|c|c|c|c|c|c|c|}
\hline \multirow{2}{*}{ Year } & \multirow{2}{*}{ Method } & \multirow{2}{*}{$\mathrm{OA}$} & \multicolumn{2}{|c|}{ Producer's accuracy } & \multicolumn{2}{|c|}{ User's accuracy } \\
\hline & & & Forest & Non-forest & Forest & Non-forest \\
\hline \multirow{2}{*}{2007} & JAXA & $84.67 \%$ & $75.81 \%$ & $100.00 \%$ & $100.00 \%$ & $70.51 \%$ \\
\hline & Proposed & $98.98 \%$ & $98.39 \%$ & $100.00 \%$ & $100.00 \%$ & $97.29 \%$ \\
\hline \multirow{2}{*}{2008} & JAXA & $89.66 \%$ & $81.49 \%$ & $100.00 \%$ & $100.00 \%$ & $81.02 \%$ \\
\hline & Proposed & $99.23 \%$ & $99.72 \%$ & $98.60 \%$ & $98.90 \%$ & $99.65 \%$ \\
\hline \multirow{2}{*}{2009} & JAXA & $92.67 \%$ & $85.64 \%$ & $100.00 \%$ & $100.00 \%$ & $86.97 \%$ \\
\hline & Proposed & $99.58 \%$ & $99.17 \%$ & $100.00 \%$ & $100.00 \%$ & $99.14 \%$ \\
\hline \multirow{2}{*}{2010} & JAXA & $99.13 \%$ & $98.64 \%$ & $99.54 \%$ & $99.45 \%$ & $98.85 \%$ \\
\hline & Proposed & $100.00 \%$ & $100.00 \%$ & $100.00 \%$ & $100.00 \%$ & $100.00 \%$ \\
\hline \multirow{2}{*}{2015} & JAXA & $94.13 \%$ & $84.32 \%$ & $99.89 \%$ & $99.78 \%$ & $91.56 \%$ \\
\hline & Proposed & $98.23 \%$ & $99.45 \%$ & $97.51 \%$ & $95.91 \%$ & $99.67 \%$ \\
\hline \multirow{2}{*}{2016} & JAXA & $96.66 \%$ & $91.26 \%$ & $99.79 \%$ & $99.60 \%$ & $95.17 \%$ \\
\hline & Proposed & $98.53 \%$ & $99.09 \%$ & $98.20 \%$ & $96.97 \%$ & $99.47 \%$ \\
\hline
\end{tabular}

\subsection{Reconstructed FR forest maps during 2011-2014}

FR forest maps for 2011-2014 were obtained to validate the reconstructing ability of the proposed approach for the ALOS data gap. In this experiment, the PALSAR/PALSAR-2 forest maps, that were prior to and after the data of prediction, were used to provide prior spatial-temporal information for the reconstructed time-series FR forest maps. With the input of the previous and later FR forest maps during 2007-2010 and 2015-2016 and generated MODIS FNF fraction maps during 2011-2014, the FR timeseries forest maps during 2011-2014 were produced for the three study areas (Figs. 7 and 8). The corresponding accuracy assessments are listed in Tables. 5 and 6. For the Paraguay study site, the first row of Fig. 7 reports the generated MODIS forest fraction maps during 2011-2014, while the FR forest maps produced by HC, RMD and STHNN are also shown to provide a comparison with the proposed approach. As STHNN is a spatial-temporal SRM method, its implementation was based on the previous provide a clearer visual comparison. 


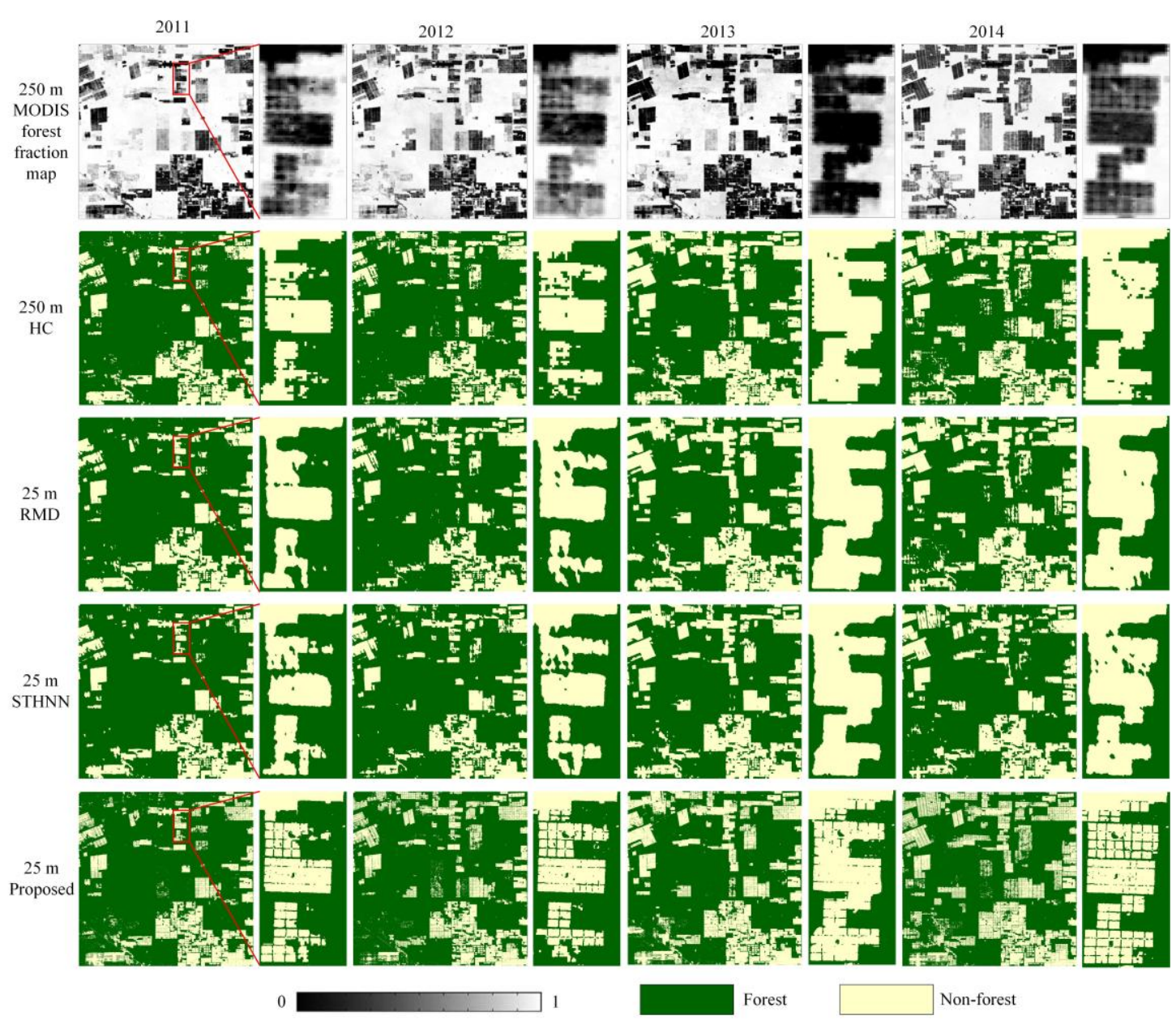

Fig. 7. MODIS forest fraction maps and reconstructed FR forest maps during 2011-2014 for the study site of Paraguay.

$$
\text { As shown in Fig. 7, it is possible to observe the deforestation process between } 2011 \text { and } 2014 \text { from }
$$

the MODIS fraction maps of forest, especially in the zoomed area. However, many forest cover change

details cannot be represented. For HC, forest feature boundaries in the resulting maps appear as jagged

patches, and many of spatial details are missing, as $\mathrm{HC}$ was performed at the coarse pixel scale of the

MODIS image. For RMD, jagged boundaries become spatially smooth and many spatial details about

the forest cover are represented. Although RMD addresses the mixed pixel problem in the MODIS image

and reduces the errors of the input MODIS FNF fraction maps, it is beyond the ability of RMD to produce

forest maps with sufficient spatial detail; for example, many small-sized linear features of forest cover

were misclassified. Compared with RMD, the boundaries of the results of the STHNN are more spatially

smooth; moreover, some linear forest features which were lost in the results of RMD were well 
represented by STHNN. This is because STHNN not only benefits from a relatively slack constraint on the fraction values of the results, but also from the abundant spatial detail of forest cover in the previous

FR forest map of 2010. However, the boundaries of STHNN results were spatially over-smoothed, and some linear forest features were mapped as local patches. In contrast, for the results of the proposed approach, more spatial details are well-represented, and the boundaries represented with appropriate smoothness. This is because temporal and spatial information was incorporated from all existing FR

Table 5. Accuracy assessment of the FR forest classifications by different approaches for the study site of Paraguay.

\begin{tabular}{|c|c|c|c|c|c|c|}
\hline \multirow{2}{*}{ Year } & \multirow{2}{*}{ Method } & \multirow{2}{*}{$\mathrm{OA}$} & \multicolumn{2}{|c|}{ Producer's accuracy } & \multicolumn{2}{|c|}{ User's accuracy } \\
\hline & & & Forest & Non-forest & Forest & Non-forest \\
\hline \multirow{4}{*}{2011} & $\mathrm{HC}$ & $87.57 \%$ & $97.08 \%$ & $80.04 \%$ & $79.41 \%$ & $97.19 \%$ \\
\hline & RMD & $82.80 \%$ & $94.38 \%$ & $73.62 \%$ & $73.94 \%$ & $94.29 \%$ \\
\hline & STHNN & $86.28 \%$ & $97.08 \%$ & $77.72 \%$ & $77.56 \%$ & $97.09 \%$ \\
\hline & Proposed & $92.45 \%$ & $99.10 \%$ & $87.17 \%$ & $85.96 \%$ & $99.19 \%$ \\
\hline \multirow{4}{*}{2012} & $\mathrm{HC}$ & $84.44 \%$ & $96.03 \%$ & $75.90 \%$ & $74.61 \%$ & $96.28 \%$ \\
\hline & RMD & $79.29 \%$ & $93.82 \%$ & $68.57 \%$ & $68.77 \%$ & $93.76 \%$ \\
\hline & STHNN & $81.44 \%$ & $97.13 \%$ & $69.87 \%$ & $68.77 \%$ & $97.06 \%$ \\
\hline & Proposed & $92.22 \%$ & $96.91 \%$ & $88.76 \%$ & $86.42 \%$ & $97.50 \%$ \\
\hline \multirow{4}{*}{2013} & $\mathrm{HC}$ & $90.78 \%$ & $94.89 \%$ & $88.09 \%$ & $83.91 \%$ & $97.50 \%$ \\
\hline & RMD & $85.60 \%$ & $89.16 \%$ & $83.27 \%$ & $77.72 \%$ & $92.15 \%$ \\
\hline & STHNN & $86.00 \%$ & $94.27 \%$ & $83.27 \%$ & $76.07 \%$ & $95.56 \%$ \\
\hline & Proposed & $94.01 \%$ & $97.14 \%$ & $91.97 \%$ & $88.79 \%$ & $98.00 \%$ \\
\hline \multirow{4}{*}{2014} & $\mathrm{HC}$ & $86.44 \%$ & $97.08 \%$ & $80.04 \%$ & $79.41 \%$ & $97.19 \%$ \\
\hline & RMD & $80.84 \%$ & $94.38 \%$ & $73.62 \%$ & $73.94 \%$ & $94.29 \%$ \\
\hline & STHNN & $79.73 \%$ & $97.08 \%$ & $77.72 \%$ & $77.56 \%$ & $97.09 \%$ \\
\hline & Proposed & $93.30 \%$ & $99.10 \%$ & $87.17 \%$ & $85.96 \%$ & $99.19 \%$ \\
\hline
\end{tabular}

Table 5 presents a summary of the accuracy assessments for the Paraguay study site. Compared to 

changes of forest cover can be visualized over this 5-year period, but it is impossible to observe how the

2011-2014 for the study sites of the USA and Russia. The corresponding accuracy assessment is provided

in Table 6. With the PALSAR/PALSAR-2 FR forest maps of 2010 and 2015 as shown in Fig. 6, the
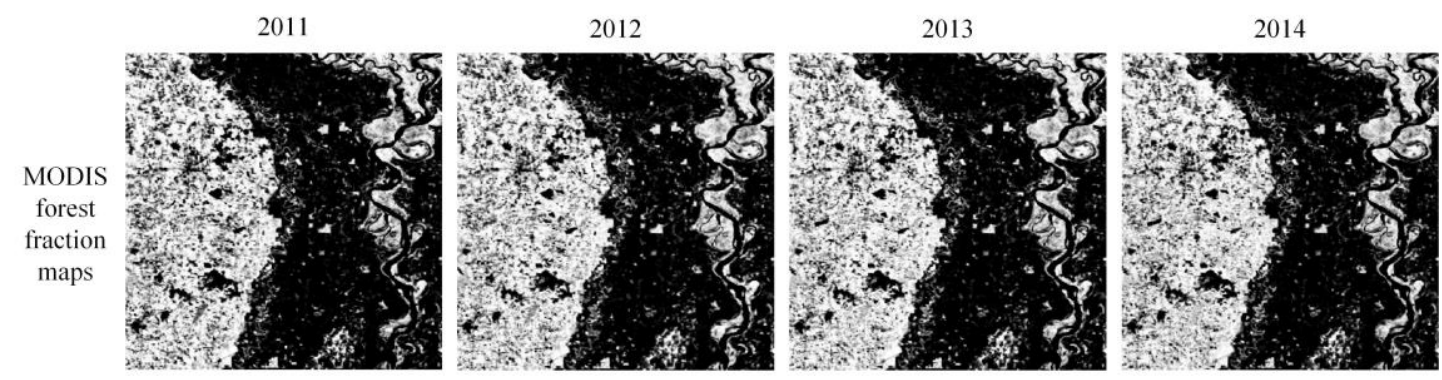
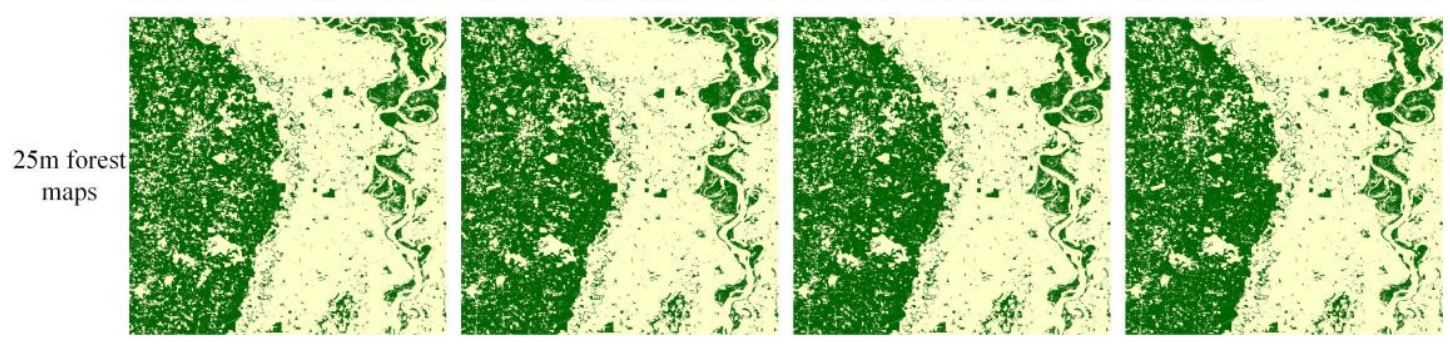

Fig. 8. MODIS forest fraction maps and reconstructed FR forest maps during 2011-2014 for the USA study site. 
581 to distinguish correctly, as they have a more complex spatial pattern.

582

583

584

585

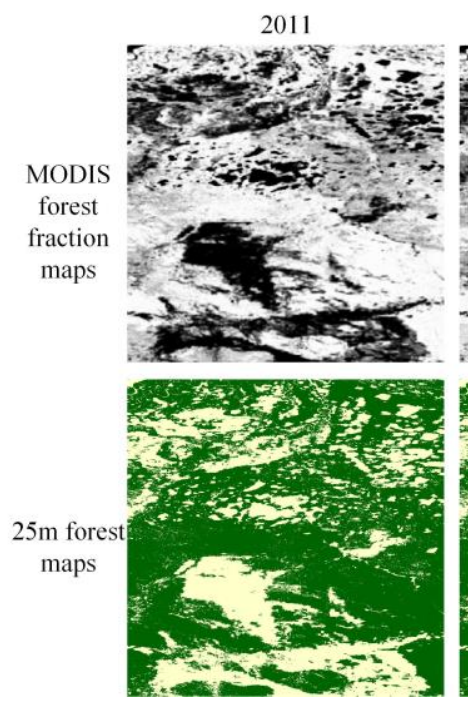

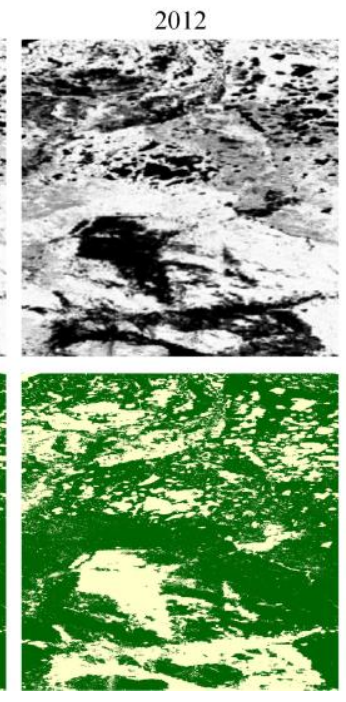

2013

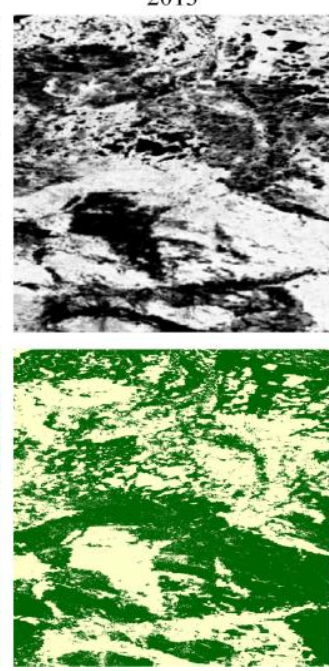

2014

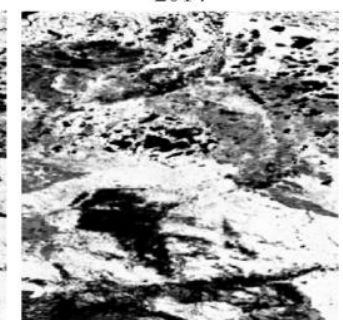

Fig. 9. MODIS forest fraction maps and reconstructed FR forest maps during 2011-2014 for the Russia study site.

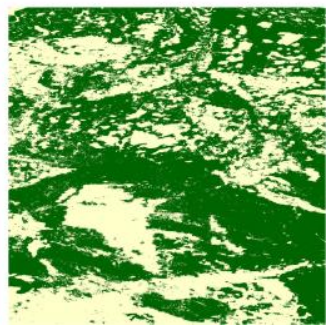

Table 6. Accuracy assessment of the FR forest maps reconstructed by the proposed approach for USA and Russia.

\begin{tabular}{ccccccc}
\hline \multirow{2}{*}{ Year } & \multirow{2}{*}{ Method } & \multirow{2}{*}{ OA } & \multicolumn{2}{c}{ Producer's accuracy } & \multicolumn{2}{c}{ User’s accuracy } \\
\cline { 4 - 7 } & & & Forest & Non-forest & Forest & Non-forest \\
\hline \multirow{6}{*}{ USA } & 2011 & $95.88 \%$ & $96.42 \%$ & $95.19 \%$ & $96.28 \%$ & $95.36 \%$ \\
& 2012 & $96.19 \%$ & $96.56 \%$ & $95.79 \%$ & $96.24 \%$ & $96.14 \%$ \\
& 2013 & $94.58 \%$ & $94.98 \%$ & $93.93 \%$ & $96.27 \%$ & $91.88 \%$ \\
& 2014 & $95.75 \%$ & $95.55 \%$ & $95.99 \%$ & $96.62 \%$ & $94.73 \%$ \\
\cline { 3 - 7 } Russia & 2011 & $94.00 \%$ & $97.97 \%$ & $87.93 \%$ & $92.54 \%$ & $96.59 \%$ \\
& 2012 & $91.50 \%$ & $96.68 \%$ & $84.88 \%$ & $89.10 \%$ & $95.24 \%$ \\
& 2013 & $91.93 \%$ & $96.66 \%$ & $84.33 \%$ & $90.83 \%$ & $94.02 \%$ \\
& 2014 & $92.34 \%$ & $95.27 \%$ & $88.01 \%$ & $92.17 \%$ & $92.62 \%$ \\
\hline
\end{tabular}

586 

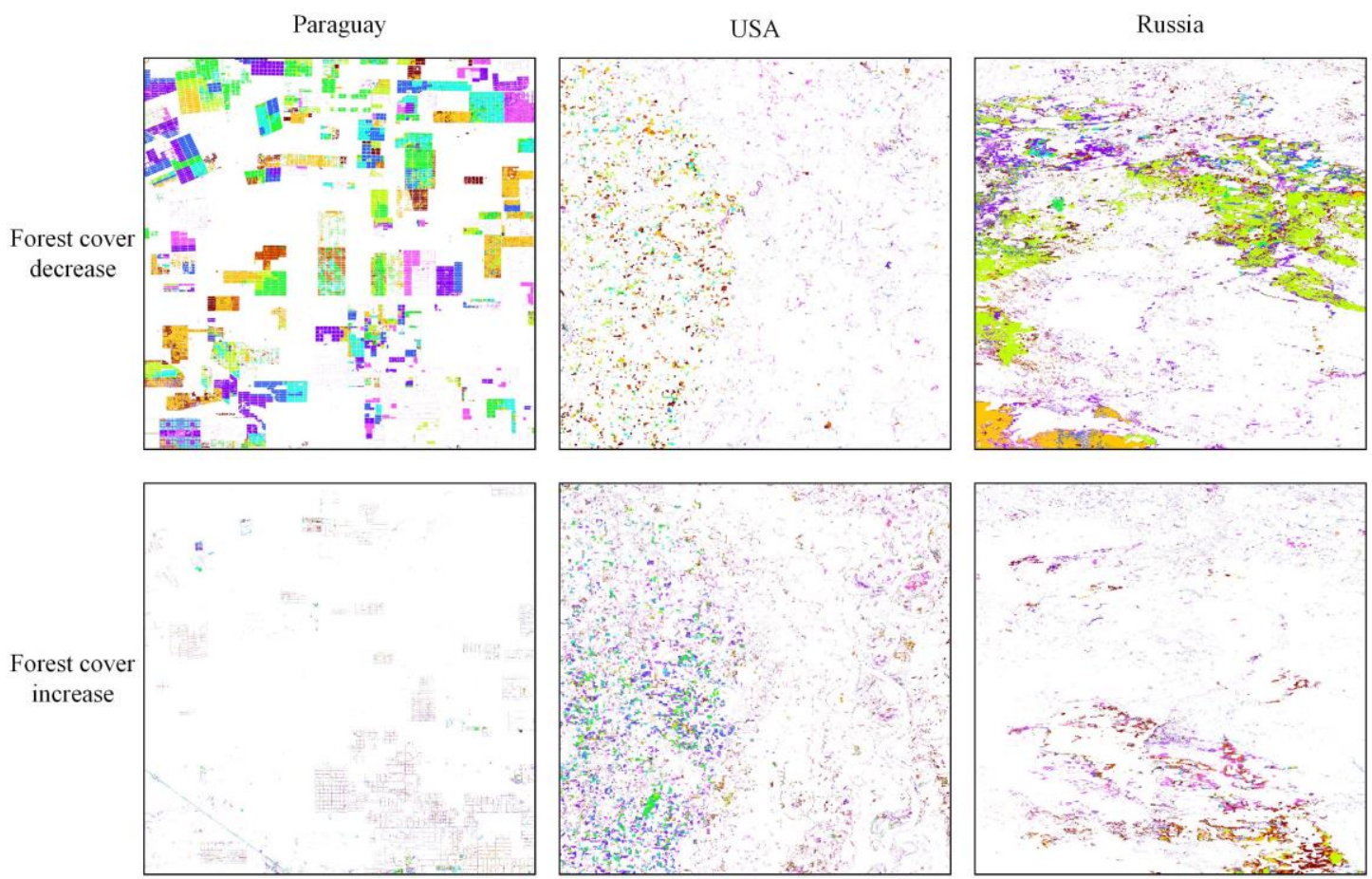

Change yea

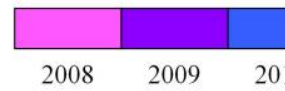

Fig. 10. Annual forest cover change maps during 2007-2016 for the three study sites.

\subsection{Annual forest cover changes during 2007-2016}

mainly focused on forest cover decrease, and there was almost no increase of forest cover from 2007 to

2016. As a tropical forest area, deforestation was the led cause of forest cover decrease in Paraguay, and 
harvesting which may result in forest cover increases and decreases were prevalent in a short-cycle, so as to maintain a balance between forest cover decreases and increases. For the study area in Russia, although there were both local decreases and increases of forest cover, the decreases were more frequent than increases. Moreover, large decreases in forest cover were observed in 2013 and 2014. Areas of forest decrease often had irregular shapes with a high degree of spatial connectivity between them. This situation may be due to the frequent forest fires that occurred in this region.

In general, forest cover decrease is caused mainly by rapid deforestation and disturbance, such as clear cutting, selective logging and forest fire, and it can generally be detected with a high degree of accuracy (Hansen et al. 2013). Compared with forest cover decreases, increases in forest cover are more complex, and greater uncertainty exists for their detection (Poorter et al. 2016). Planting and regrowth are two principle sources of forest cover increases. Planting is associated with extensive forestry; the increase in forest cover in the USA study site is typical of forest planting. On the other hand, forest regrowth where trees regrow naturally from some past deforestation and disturbance includes two main cases: 1) regrowth from forest clear cut (deforestation), where recovery is generally a slow process. This is one of the reasons why forest cover decrease was small in Paraguay during 2007-2016;2) regrowth from forest fire (disturbances). If the fire is sufficiently limited, it can leave the trunks of trees relatively intact, which opens the possibility for the burnt trees to regrow within a short time (Chu and Guo 2014). This is why many forest cover decreases were observed in the Russia study site. This issue will be discussed further in the following section. 


\subsection{Multi-scale image fusion}

This research aimed to produce annual $25 \mathrm{~m}$ forest maps by fusing PALSAR/PALSAR-2 and MODIS NDVI images over the period 2007-2016. As PALSAR/PALSAR-2 and MODIS NDVI images have different spatial resolutions, the image fusion in this study was implemented with a multi-scale approach. There are two types of multi-scale operations: the first is the production of FR forest maps from PALSAR/PALSAR-2 images by integrating MODIS NDVImax; the second is the production of FR forest maps from MODIS NDVI images by integrating generated PALSAR/PALSAR-2 forest maps. The first multi-scale image fusion approach focuses on the PALSAR/PALSAR-2 images, where the MODIS NDVImax was used as additional information in the decision tree algorithm to increase the classification accuracy. This type of image fusion method has been applied widely to extract forest maps from SAR images and optical satellite sensor images (Chen et al. 2018; Dong et al. 2012; Qin et al. 2017). The second multi-scale image fusion method is a full spatial-temporal SRM method, so as to take advantage of the fine scale information about the forest cover distributions in existing FR forest maps (Li et al. 2014a; Zhang et al. 2017a; Zhang et al. 2017b). Although the output of both these multi-scale image fusion methods is the FR forest map, there is a downscaling process in the second multi-scale image fusion method compared with the first one. It is noteworthy that producing FR forest maps from CR 
process (Ling et al. 2016). Fortunately, the proposed new spatial-temporal SRM method as described in section 3.3 can take advantage of all the existing FR forest maps during 2007-2010 and 2015-2016, which can significantly decrease the uncertainty in downscaling compared with traditional SRM methods. Despite the factor that the above two multi-scale fusion methods focus on different objectives, it was necessary to combine them to produce the FR forest maps during 2007-2016. This is because the second multi-scale image fusion task is highly dependent on the FR forest maps produced by the first multi-scale image fusion method; therefore, increasing the accuracies of FR forest maps during 2007-2010 and 20152016 provided more accurate prior information for the second multi-scale fusion method, and finally the constructed FR forest maps during 2011-2014, when this is a gap in data from PALSAR systems.

\subsection{Advantages and computational efficiency of the proposed approach}

Global PALSAR/PALSAR-2 forest maps produced by JAXA contain abundant prior information about forest cover and forest cover change. The proposed approach aimed to inherit the implicit advantages associated with the time-series of $250 \mathrm{~m}$ MODIS NDVI images and the existing PALSAR/PALSAR-2 forest maps, and thus, achieve high accuracy in the reconstructed FR forest maps during 2011-2014 when PALSAR data are unavailable. The superiority and advantages of the proposed approach were demonstrated in the above experiments. In this research, the experiments focused on three distinct types of forests, due to their crucial importance in global biogeochemical cycles. However, the method could be applied anywhere on the Earth's surface, because the MODIS NDVI product and PALSAR/PALSAR-2 forest maps are now available at the global scale. Generally, the advantages of the proposed approach are the utilization of the abundant prior information within all existing FR forest maps during 2007-2010 and 2015-2016, and more specifically: 
1) Integrating PALSAR/PALSAR-2 and MODIS NDVI data to produce more accurate FR forest maps during 2007-2010 and 2015-2016, thus contributing greatly to the reconstructed FR forest maps during 2011-2014.

2) Using existing FR forest maps and annual MODIS NDVI images to estimate $250 \mathrm{~m}$ FNF fraction maps during 2011-2014 automatically. Moreover, it is noteworthy that annual timeseries MODIS NDVI images contain abundant phenological information about different types of forests around the world and are, thus, suitable for estimating FNF fraction maps for various forests.

3) Traditional spatial-temporal SRM models can only use one or two existing FR land cover maps to build the spatial-temporal regularization term and cannot deal with land cover change through time (Li et al. 2017; Zhang et al. 2017b). In contrast, the proposed approach applies all FR forest maps during 2007-2010 and 2015-2016 to construct the spatial-temporal regularization term, so as to provide more useful prior information for the reconstructed FR forest maps.

The MATLAB platform (MATLAB R2018a version) on an Intel(R) Core (TM) i7-7700K Processor at $4.20 \mathrm{GHz}$ was used for the reconstruction and validation of the proposed approach. As described above, there are three parts (section 3.1, 3.2 and 3.3) to the proposed approach. To assess the computational efficiency, Table 7 lists the computational cost of the three parts. The total computational time of the proposed approach for one study site, Paraguay, in this research was 2936.27 s, the first two parts spent little time (less than $5 \%$ of the total computation time), but part 3 took up 2812.41 s, which is more than $95 \%$ of the total computational time. Compared with the first two parts, part 3 is based on an optimization problem, and iteration is required in the search for the optimal solution. An alternative solution to this is 
replacing the iteration-based optimization problem as a maximum posterior probability (MAP) problem (Atkinson 2005; Wang et al. 2014), so as to decrease the computational time. On the other hand, given the great superiority of parallelization (Christophe et al. 2011), it is of major interest to build a platform based on parallelization to significantly reduce the computational time of the proposed algorithm.

Table 7. Computation cost of different parts in the proposed approach.

\begin{tabular}{ccccc}
\hline & Part 1(section 3.1) & Part 2(section 3.2) & Part 3(section 3.3) & Total \\
\hline Paraguay & $52.93 \mathrm{~s}$ & $70.93 \mathrm{~s}$ & $2812.41 \mathrm{~s}$ & $2936.27 \mathrm{~s}$ \\
\hline
\end{tabular}

\subsection{Effect of existing FR forest maps}

For the proposed approach, prior temporal information from existing FR forest maps could be exploited for the newly generated FR forest map. The proposed approach has the advantage to extract prior information from all existing FR forest maps, which equate to the PALSAR/PALSAR-2 forest maps during 2007-2010 and 2015-2016 in this research. Table 8 was used to measure the effect of existing FR forest maps, and it reports the accuracies of the FR forest maps generated by the proposed approach based on different numbers of existing FR forest maps for the Paraguay study site. When only one existing FR forest map (2007) was used for the proposed approach, the result achieved the smallest OA values, because there was not much prior temporal information in the FR forest map in 2007. However, with the continuous increase in the number of FR forest maps, the accuracies of the resultant forest maps increased. In particular, when the FR forest map for 2015 was added, the OA value increased by $6.48 \%$ compared with the result based on FR forest maps during 2007-2010. This is because serious forest cover changes that happened during 2013-2015 and the later FR forest map in 2015 was able to provide more prior information about the process of forest change. When the FR forest map in 2016 was added, a further increase in accuracy was observed, with the largest $\mathrm{OA}(94.01 \%)$ values, which demonstrates that existing FR forest maps (both previous and later) could have a positive effect on the result of the proposed 
approach. It is suggested that both previous and later FR forest maps are added when applying the proposed approach to reconstruct FR forest maps.

Table 8. Accuracy assessment of the FR forest maps generated by the proposed approach based on different numbers of existing FR forest maps for Paraguay.

\begin{tabular}{cc}
\hline Existing FR forest maps used & OA \\
\hline 2007 & $82.12 \%$ \\
$2007 / 2008$ & $83.01 \%$ \\
$2007 / 2008 / 2009$ & $84.55 \%$ \\
$2007 / 2008 / 2009 / 2010$ & $86.89 \%$ \\
$2007 / 2008 / 2009 / 2010 / 2015$ & $93.37 \%$ \\
$2007 / 2008 / 2009 / 2010 / 2015 / 2016$ & $94.01 \%$ \\
\hline
\end{tabular}

\subsection{Forest cover change in the study site of Russia}

In Fig. 9, it is observed that some pixels of forest cover disappeared and re-appeared from 2012 to 2014 (clearly illustrated by the red ellipse of Fig. 11). Generally, it is physically impossible for forest cover to remove and re-appear within a very short time (Chazdon 2003; Nguyen et al. 2018). If a tree is clearly cut in one year, it will be impossible for it to regrow into a mature tree in the next year (which is the "case 1" in Fig. 11), because recovery from forest clear cutting is a slow process (Nguyen et al. 2018). In the real situation, besides forest clear cutting (case 1 in Fig. 11), forest disturbances, such as forest fire (case 2 in Fig.11), can also result in a reduction of forest cover. However, unlike forest clear cutting, some forest fire can leave the complete trunks of trees, which make recovery to large trees in the next year possible (Chu and Guo 2014; Lhermitte et al. 2011). To find out the cause of forest cover change (in the red oval) during 2012-2014 for the study site of Russia, the corresponding annual Google Earth images were illustrated. From the Google Earth images, it can be seen that a large area of forest fire occurred across the study site in 2013, reducing the forest cover; but in 2014, some of the lost forest cover exhibited a good recovery and regrew as forest cover again. This suggests that the forest cover disappearance and re-appearance in the study site of Russia belong to "case 2", and is reasonable. 


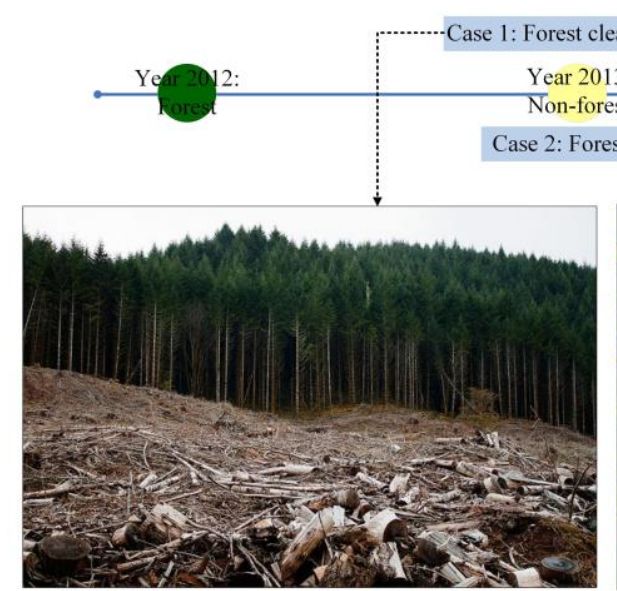

Case 1: Forest clear cutting (deforestation)
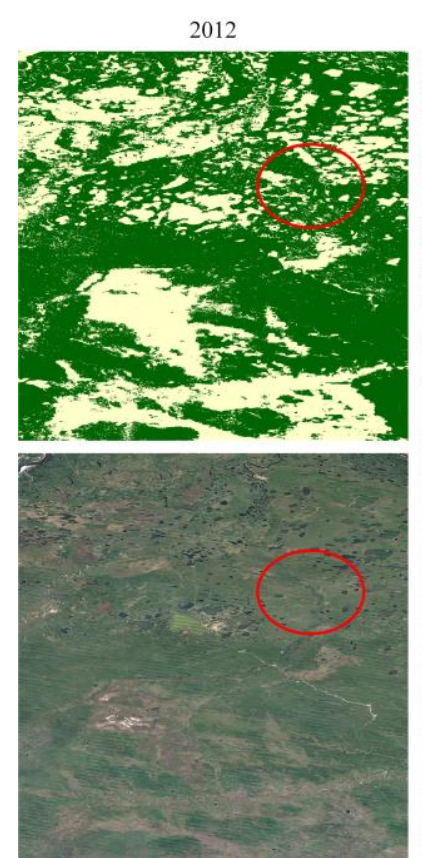
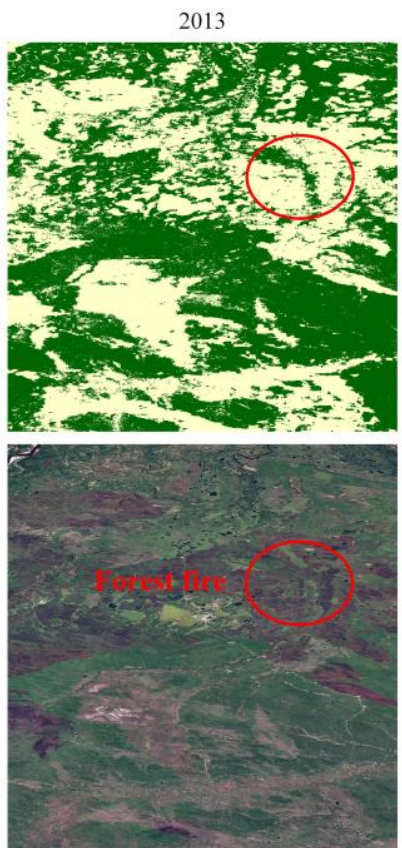

Regrowth: impossible

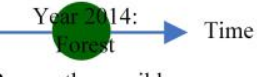

Regrowth: possible

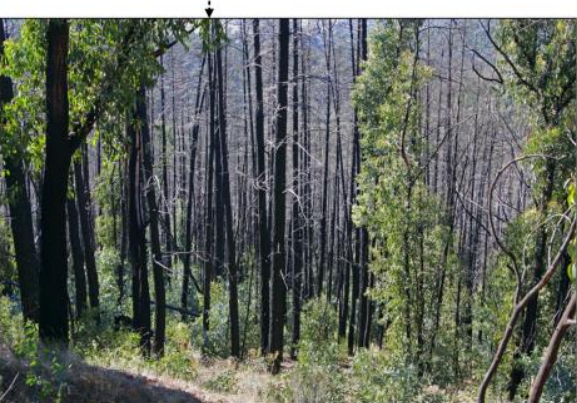

Case 2: Forest fires (disturbance)
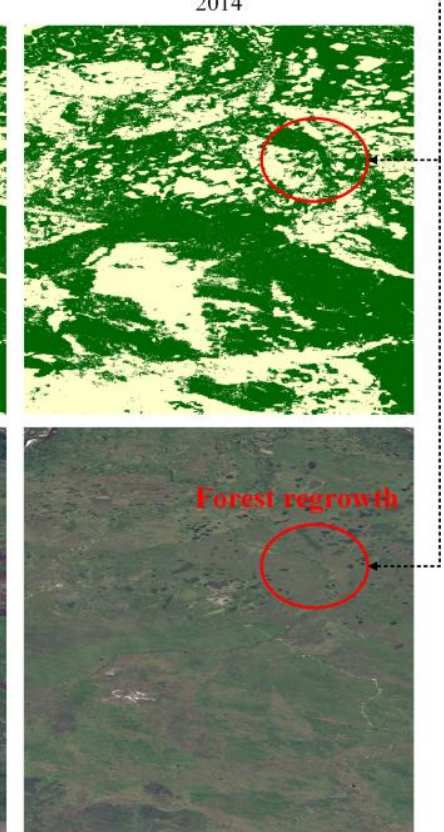

Figure 11. Forest cover change during 2012-2014 for the study site of Russia.

\subsection{Uncertainty in forest cover increase}


greater uncertainty (Bullock et al. 2018; Nguyen et al. 2018). For the case of forest clear cutting, it is impossible for a lost forest cover to recover (increase) within 1-to-2 years, and a constraint is needed for the proposed algorithm to prevent rapid "switching" from one class to another within a short time. However, for the case shown in Section 5.4, the rapid "switching" is reasonable for recovery from forest fire, and in this case, a constraint on rapid "switching" would lead to additional errors. In real applications, it is difficult to separate the two cases of forest cover increase (recovery) shown in Fig. 11. Therefore, uncertainty exists for forest cover increases in the time-series forest maps reconstructed by the proposed method.

For monitoring of forest cover recovery processes, simply defining the pixel as forest or non-forest is not sufficient. For example, the tree canopy cover for a pixel in 2012 was $60 \%$, and then the pixel was defined as forest cover. In 2013 , the tree canopy cover for the pixel increased to $80 \%$ and the pixel was also defined as forest cover. If we just focused on the class labels of the pixel, there would be no changes from 2012 to 2013 ("forest" to "forest"), but the canopy cover increased from $60 \%$ to $80 \%$. Therefore, instead of simply using the class labels of forest and non-forest to monitor the forest cover recovery process, some other continuous variables, such as tree canopy cover (Sexton et al. 2013), forest proportion (Zhang et al. 2018), aboveground biomass (Foody et al. 2001), and the Normalized Degradation Fraction Index (NDFI) (Bullock et al. 2018), may be a better choice. Moreover, although remote sensing has contributed a lot to the detection of successive processes related to forest recovery, ground sample plots remain indispensable due to the uncertainty related to forest recovery processes 


\subsection{Error sources and future research}

Reconstructing FR forest maps during 2011-2014 by fusing ALOS PALSAR and MODIS NDVI data is an ill-posed problem. The proposed approach aims to decrease the uncertainty in the fusion process by taking advantages of prior information within the pre- and post- PALSAR/PALSAR-2 FR forest maps. However, uncertainty caused by different error sources is present, especially in the spatialtemporal SRM model (Atkinson et al. 2008; Turner et al. 2003). When applying the proposed approach, three main error sources may impose a considerable negative effect on the results. Firstly, since the proposed approach is based on the annual time-series MODIS NDVI and PALSAR/PALSAR-2 forest maps, data quality may impact directly the accuracy of the reconstructed forest maps. As MODIS is an optical satellite sensor, the quality of the MODIS NDVI images is affected by cloud cover, especially in tropical rain forest areas where cloud-free images are rare (Friedl et al. 2002; Montesano et al. 2009; Platnick et al. 2003). The Savitzky-Golay filter was, thus, applied to the time-series MODIS NDVI images to decrease the influence of abnormal pixel values caused by cloud cover. Moreover, the quality of the FR forest map extracted from the integrated PALSAR and MODIS NDVImax images varies from place-to-place, because the PALSAR data cannot capture all of the complex spatial features of the diverse forest covers on the Earth's surface (Shimada et al. 2014; Walker et al. 2010). Therefore, it is challenging to ensure that all of the reconstructed FR forest maps have the same high accuracy values, and this was indicated in the above results of the three study sites. The second error source is the estimation of the MODIS FNF fraction maps from time-series MODIS NDVI images. KRR was used as a nonlinear regression method to predict the FNF fraction maps, because KRR is a robust method and there are a few parameters to be set. However, besides KRR, alternative methods such as deep learning approaches (Dong et al. 2016; Zhang et al. 2016) could be used. The third source of uncertainty is the parameter 

equation (2) is important for the reconstruction of FR forest maps, and automatic method is suggested to

777 predict the optimal values of the two parameters (Li et al. 2012).

778 
The global, annual $25 \mathrm{~m}$ PALSAR/PALSAR-2 forest maps produced during 2007-2010 and 20152016 represent the first satellite-derived, annual, global forest map product. However, PALSAR forest maps between 2011 and 2014 are missing. This research demonstrated a new approach that has great potential for reconstructing the missing FR PALSAR forest maps and producing more accurate FR PALSAR forest classifications based on synchronous MODIS NDVI and asynchronous PALSAR/PALSAR-2 images, opening up the potential for a wide range of applications using these data.

This is significant because the world's forests represent a unique natural resource that is under threat

(Hansen et al. 2013). The world's forests represent a crucial life support system, not least in relation to an increasing global population generally, and the ecosystem services that forests provide are fundamental to the survival of local human populations across most parts of the world where forests exist (Foley et al. 2005). It is, thus, crucial that tools are designed for the precise monitoring of forests globally (Curtis et al. 2018). The failure of ALOS PALSAR communication was unfortunate, but the method proposed here can fill the resulting four-year gap, crucially allowing continuous time-series, fine spatial resolution, global forest monitoring going back to 2007 and extending into the future via PALSAR-2. classifications during 2007-2010 and 2015-2016 were generated from the integrated PALSAR/PALSAR2 and MODIS NDVI images with a decision tree algorithm. In the second stage, annual MODIS FNF fraction maps between 2011 and 2014 were estimated using the nonlinear regression method of KRR. 
Finally, a new spatial-temporal SRM model was developed to produce the missing annual FR forest maps during 2011-2014. Compared to three benchmark methods, the proposed approach produced FR forest classifications with the greatest visual and quantitative quality and was able to capture annual FR forest cover changes during the entire period 2007-2016 for all three study sites, which represent the world's three main forest types: tropical forest, temperate broadleaf and mixed forest and boreal forest.

Some key possibilities can be pursued in future research to further improve the accuracy of the method. Firstly, it would be possible to use some open access and cloud-free FR satellite sensor images, including the ASTER multispectral images (with a spatial resolution of $15 \mathrm{~m}$ ) and Landsat series images during 2011-2014, as additional datasets to produce the FR forest maps within some local regions. Secondly, for places where open access and cloud-free fine spatial resolution satellite sensor images are available, the corresponding FR forest maps can be regarded as a new starting point to reconstruct the FR forest maps.

\section{Acknowledgments}

The authors wish to thank JAXA for providing the PALSAR/PALSAR-2 forest maps. This work was supported by the Strategic Priority Research Program of Chinese Academy of Sciences (Grant No. XDA2003030201), National Natural Science Foundation of China (Grant No. 41801292), Natural Science Foundation of Hubei Province of China (Grant No. ZRMS2018001622), Youth Innovation Promotion Association CAS (Grant No. 2017384), and the Natural Science Foundation of China (Grant No. 61671425). 
Achard, F., \& Estreguil, C., 1995. Forest classification of Southeast Asia using NOAA AVHRR data. Remote Sens. Environ. 54:198-208. http://dx.doi.org/10.1016/0034-4257(95)00153-0.

Alexander, K., Jessica, L.M., Peter, P., Tatiana, L., Alexandra, T., Svetlana, T., et al., 2014. Remote sensing estimates of stand-replacement fires in Russia, 2002-2011. Environ. Res. Lett. 9:105007. http://dx.doi.org/10.1088/17489326/9/10/105007.

An, S., Liu, W., \& Venkatesh, S., 2007. Fast cross-validation algorithms for least squares support vector machine and kernel ridge regression. Pattern Recognit. 40:2154-2162. http://dx.doi.org/10.1016/j.patcog.2006.12.015.

Atkinson, P.M., 1997. Mapping sub-pixel boundaries from remotely sensed images. Innovations in GIS 4:166-180. http://dx.doi.org/

Atkinson, P.M., 2005. Sub-pixel target mapping from soft-classified, remotely sensed imagery. Photogramm. Eng. Remote Sens. 71:839-846. http://dx.doi.org/10.14358/PERS.71.7.839.

Atkinson, P.M., 2013. Downscaling in remote sensing. Int. J. Appl. Earth Obs. 22:106-114. http://dx.doi.org/10.1016/j.jag.2012.04.012.

Atkinson, P.M., Pardo-Iguzquiza, E., \& Chica-Olmo, M., 2008. Downscaling Cokriging for SuperResolution Mapping of Continua in Remotely Sensed Images. IEEE Trans. Geosci. Remote Sens. 46:573-580. http://dx.doi.org/10.1109/TGRS.2007.909952.

Bartholome, E., \& Belward, A.S., 2005. GLC2000: a new approach to global land cover mapping from Earth observation data. Int. J. Remote Sens. 26:1959-1977. http://dx.doi.org/10.1080/01431160412331291297.

Beck, P.S.A., Atzberger, C., Høgda, K.A., Johansen, B., \& Skidmore, A.K., 2006. Improved monitoring of vegetation dynamics at very high latitudes: A new method using MODIS NDVI. Remote Sens. Environ. 100:321-334. http://dx.doi.org/10.1016/j.rse.2005.10.021.

Besag, J., 1986. On the Statistical-Analysis of Dirty Pictures. J. R. Stat. Soc. Ser. B-Stat. 48:259-302. http://dx.doi.org/

Bicheron, P., Amberg, V., Bourg, L., Petit, D., Huc, M., Miras, B., et al., 2011. Geolocation Assessment of MERIS GlobCover Orthorectified Products. IEEE Trans. Geosci. Remote Sens. 49:2972-2982. http://dx.doi.org/10.1109/Tgrs.2011.2122337.

Bioucas-Dias, J.M., Plaza, A., Dobigeon, N., Parente, M., Du, Q., Gader, P., et al., 2012. Hyperspectral Unmixing Overview: Geometrical, Statistical, and Sparse Regression-Based Approaches. IEEE J. Sel. Top. Appl. Earth Observ. Remote Sens. 5:354-379. http://dx.doi.org/10.1109/JSTARS.2012.2194696.

Bullock, E.L., Woodcock, C.E., \& Olofsson, P., 2018. Monitoring tropical forest degradation using spectral unmixing and Landsat time series analysis. Remote Sens. Environ.10.1016/j.rse.2018.11.011.

Canadell, J.G., \& Raupach, M.R., 2008. Managing Forests for Climate Change Mitigation. Science 320:1456-1457. http://dx.doi.org/10.1126/science.1155458.

Chazdon, R.L., 2003. Tropical forest recovery: legacies of human impact and natural disturbances. Perspectives in Plant Ecology, Evolution and Systematics 6:51-71. http://dx.doi.org/10.1078/14338319-00042.

Chazdon, R.L., Broadbent, E.N., Rozendaal, D.M.A., Bongers, F., Zambrano, A.M.A., Aide, T.M., et al., 
2016. Carbon sequestration potential of second-growth forest regeneration in the Latin American tropics. Science Advances 2:e1501639. http://dx.doi.org/10.1126/sciadv.1501639.

Chen, B., Xiao, X., Ye, H., Ma, J., Doughty, R., Li, X., et al., 2018. Mapping Forest and Their SpatialTemporal Changes From 2007 to 2015 in Tropical Hainan Island by Integrating ALOS/ALOS-2 LBand SAR and Landsat Optical Images. IEEE J. Sel. Top. Appl. Earth Observ. Remote Sens. 11:852867. http://dx.doi.org/10.1109/JSTARS.2018.2795595.

Chen, J., Jönsson, P., Tamura, M., Gu, Z., Matsushita, B., \& Eklundh, L., 2004. A simple method for reconstructing a high-quality NDVI time-series data set based on the Savitzky-Golay filter. Remote Sens. Environ. 91:332-344. http://dx.doi.org/10.1016/j.rse.2004.03.014.

Christophe, E., Michel, J., \& Inglada, J., 2011. Remote Sensing Processing: From Multicore to GPU. IEEE J. Sel. Top. Appl. Earth Observ. Remote Sens. 4:643-652. http://dx.doi.org/10.1109/JSTARS.2010.2102340.

Chu, T., \& Guo, X., 2014. Remote Sensing Techniques in Monitoring Post-Fire Effects and Patterns of Forest Recovery in Boreal Forest Regions: A Review. Remote Sens. 6:470. http://dx.doi.org/10.3390/rs6010470.

Curtis, P.G., Slay, C.M., Harris, N.L., Tyukavina, A., \& Hansen, M.C., 2018. Classifying drivers of global forest loss. Science 361:1108-1111. http://dx.doi.org/10.1126/science.aau3445.

DiMiceli, C., Carroll, M., Sohlberg, R., Huang, C., Hansen, M., \& Townshend, J., 2011. Annual global automated MODIS vegetation continuous fields (MOD44B) at $250 \mathrm{~m}$ spatial resolution for data years beginning day 65, 2000-2010, collection 5 percent tree cover. USA: University of Maryland, College Park, $M D$

Dong, C., Loy, C.C., He, K.M., \& Tang, X.O., 2016. Image Super-Resolution Using Deep Convolutional Networks. IEEE Trans. Pattern Anal. Mach. Intell. 38:295-307. http://dx.doi.org/10.1109/Tpami.2015.2439281.

Dong, J.W., Xiao, X.M., Sheldon, S., Biradar, C., Duong, N.D., \& Hazarika, M., 2012. A comparison of forest cover maps in Mainland Southeast Asia from multiple sources: PALSAR, MERIS, MODIS and FRA. Remote Sens. Environ. 127:60-73. http://dx.doi.org/10.1016/j.rse.2012.08.022.

Dong, J.W., Xiao, X.M., Sheldon, S., Biradar, C., Zhang, G.L., Duong, N.D., et al., 2014. A 50-m Forest Cover Map in Southeast Asia from ALOS/PALSAR and Its Application on Forest Fragmentation Assessment. Plos One 9:1-12. http://dx.doi.org/10.1371/journal.pone.0085801.

Evans, T.L., Costa, M., Telmer, K., \& Silva, T.S.F., 2010. Using ALOS/PALSAR and RADARSAT-2 to Map Land Cover and Seasonal Inundation in the Brazilian Pantanal. IEEE J. Sel. Top. Appl. Earth Observ. Remote Sens. 3:560-575. http://dx.doi.org/10.1109/Jstars.2010.2089042.

Fang, J.Y., Chen, A.P., Peng, C.H., Zhao, S.Q., \& Ci, L., 2001. Changes in forest biomass carbon storage in China between 1949 and 1998. Science 292:2320-2322. http://dx.doi.org/10.1126/science.1058629.

FAO (2010). Global forest resources assessment 2010. In U.N. (Ed.). Rome, Italy

Foley, J.A., DeFries, R., Asner, G.P., Barford, C., Bonan, G., Carpenter, S.R., et al., 2005. Global consequences of land use. Science 309:570-574. http://dx.doi.org/10.1126/science.1111772.

Foody, G.M., 1998. Sharpening fuzzy classification output to refine the representation of sub-pixel land cover distribution. Int. J. Remote Sens. 19:2593-2599. http://dx.doi.org/10.1080/014311698214659.

Foody, G.M., Cutler, M.E., McMorrow, J., Pelz, D., Tangki, H., Boyd, D.S., et al., 2001. Mapping the biomass of Bornean tropical rain forest from remotely sensed data. Glob. Ecol. Biogeogr. 10:379387. http://dx.doi.org/10.1046/j.1466-822X.2001.00248.x. 
Foody, G.M., \& Doan., H.T.X., 2007. Variability in soft classification prediction and its implications for sub-pixel scale change detection and super resolution mapping. Photogramm. Eng. Remote Sens. 73:923-933. http://dx.doi.org/10.14358/PERS.73.8.923.

Friedl, M.A., McIver, D.K., Hodges, J.C.F., Zhang, X.Y., Muchoney, D., Strahler, A.H., et al., 2002. Global land cover mapping from MODIS: algorithms and early results. Remote Sens. Environ. 83:287-302. http://dx.doi.org/10.1016/S0034-4257(02)00078-0.

Ge, Y., Li, S.P., \& Lakhan, V.C., 2009. Development and Testing of a Subpixel Mapping Algorithm. IEEE Trans. Geosci. Remote Sens. 47:2155-2164. http://dx.doi.org/10.1109/TGRS.2008.2010863.

Gillespie, T.W., Foody, G.M., Rocchini, D., Giorgi, A.P., \& Saatchi, S., 2008. Measuring and modelling biodiversity from space. Prog. Phys. Geogr. 32:203-221. http://dx.doi.org/10.1177/0309133308093606.

Giri, C., Zhu, Z., \& Reed, B., 2005. A comparative analysis of the Global Land Cover 2000 and MODIS land cover data sets. Remote Sens. Environ. 94:123-132. http://dx.doi.org/10.1016/j.rse.2004.09.005.

Gong, P., Wang, J., Yu, L., Zhao, Y.C., Zhao, Y.Y., Liang, L., et al., 2013. Finer resolution observation and monitoring of global land cover: first mapping results with Landsat TM and ETM+ data. Int. J. Remote Sens. 34:2607-2654. http://dx.doi.org/10.1080/01431161.2012.748992.

Gu, Y.X., Brown, J.F., Verdin, J.P., \& Wardlow, B., 2007. A five - year analysis of MODIS NDVI and NDWI for grassland drought assessment over the central Great Plains of the United States. Geophys. Res. Lett. 34:1-6. http://dx.doi.org/10.1029/2006GL029127.

Hansen, M.C., DeFries, R.S., Townshend, J.R.G., Carroll, M., Dimiceli, C., \& Sohlberg, R.A., 2003. Global Percent Tree Cover at a Spatial Resolution of 500 Meters: First Results of the MODIS Vegetation Continuous Fields Algorithm. Earth Interact. 7:1-15. http://dx.doi.org/10.1175/10873562(2003)007<0001:GPTCAA>2.0.CO;2.

Hansen, M.C., Potapov, P.V., Moore, R., Hancher, M., Turubanova, S.A., Tyukavina, A., et al., 2013. High-Resolution Global Maps of 21st-Century Forest Cover Change. Science 342:850-853. http://dx.doi.org/10.1126/science.1244693.

Hansen, M.C., Roy, D.P., Lindquist, E., Adusei, B., Justice, C.O., \& Altstatt, A., 2008. A method for integrating MODIS and Landsat data for systematic monitoring of forest cover and change in the Congo Basin. Remote Sens. Environ. 112:2495-2513. http://dx.doi.org/10.1016/j.rse.2007.11.012.

Hansen, M.C., Stehman, S.V., Potapov, P.V., Arunarwati, B., Stolle, F., \& Pittman, K., 2009. Quantifying changes in the rates of forest clearing in Indonesia from 1990 to 2005 using remotely sensed data sets. Environ. Res. Lett. 4:1-12. http://dx.doi.org/10.1088/1748-9326/4/3/034001.

Jin, S.M., \& Sader, S.A., 2005a. Comparison of time series tasseled cap wetness and the normalized difference moisture index in detecting forest disturbances. Remote Sens. Environ. 94:364-372. http://dx.doi.org/10.1016/j.rse.2004.10.012.

Jin, S.M., \& Sader, S.A., 2005b. MODIS time-series imagery for forest disturbance detection and quantification of patch size effects. Remote Sens. Environ. 99:462-470. http://dx.doi.org/10.1016/j.rse.2005.09.017.

Kaptué Tchuenté, A.T., Roujean, J.-L., \& De Jong, S.M., 2011. Comparison and relative quality assessment of the GLC2000, GLOBCOVER, MODIS and ECOCLIMAP land cover data sets at the African continental scale. Int. J. Appl. Earth Obs. 13:207-219. http://dx.doi.org/10.1016/j.jag.2010.11.005.

Kasetkasem, T., Arora, M.K., \& Varshney, P.K., 2005. Super-resolution land cover mapping using a Markov random field based approach. Remote Sens. Environ. 96:302-314. 
http://dx.doi.org/10.1016/j.rse.2005.02.006.

Kauppi, P.E., Mielikäinen, K., \& Kuusela, K., 1992. Biomass and Carbon Budget of European Forests, 1971 to 1990. Science 256:70-74. http://dx.doi.org/10.1126/science.256.5053.70.

Keshava, N., \& Mustard, J.F., 2002. Spectral unmixing. IEEE Signal Proc. Mag. 19:44-57. http://dx.doi.org/10.1109/79.974727.

Kim, K.I., \& Kwon, Y., 2010. Single-Image Super-Resolution Using Sparse Regression and Natural Image Prior. IEEE Trans. Pattern Anal. Mach. Intell. 32:1127-1133. http://dx.doi.org/10.1109/TPAMI.2010.25.

Lhermitte, S., Verbesselt, J., Verstraeten, W.W., Veraverbeke, S., \& Coppin, P., 2011. Assessing intraannual vegetation regrowth after fire using the pixel based regeneration index. ISPRS-J. Photogramm. Remote Sens. 66:17-27. http://dx.doi.org/10.1016/j.isprsjprs.2010.08.004.

Li, X.D., Du, Y., \& Ling, F., 2012. Spatially adaptive smoothing parameter selection for Markov random field based sub-pixel mapping of remotely sensed images. Int. J. Remote Sens. 33:7886-7901. http://dx.doi.org/10.1080/01431161.2012.703347.

Li, X.D., Du, Y., \& Ling, F., 2014a. Super-Resolution Mapping of Forests With Bitemporal Different Spatial Resolution Images Based on the Spatial-Temporal Markov Random Field. IEEE J. Sel. Top. Appl. Earth Observ. Remote Sens. 7:29-39. http://dx.doi.org/10.1109/JSTARS.2013.2264828.

Li, X.D., Ling, F., Du, Y., Feng, Q., \& Zhang, Y.H., 2014b. A spatial-temporal Hopfield neural network approach for super-resolution land cover mapping with multi-temporal different resolution remotely sensed images. ISPRS-J. Photogramm. Remote Sens. 93:76-87. http://dx.doi.org/10.1016/j.isprsjprs.2014.03.013.

Li, X.D., Ling, F., Foody, G.M., Ge, Y., Zhang, Y.H., \& Du, Y., 2017. Generating a series of fine spatial and temporal resolution land cover maps by fusing coarse spatial resolution remotely sensed images and fine spatial resolution land cover maps. Remote Sens. Environ. 196:293-311. http://dx.doi.org/10.1016/j.rse.2017.05.011.

Ling, F., Du, Y., Li, X.D., Li, W.B., Xiao, F., \& Zhang, Y.H., 2013. Interpolation-based super-resolution land cover mapping. Remote Sens. Lett. 629-638. http://dx.doi.org/10.1080/2150704X.2013.781284.

Ling, F., Foody, G.M., Li, X.D., Zhang, Y.H., \& Du, Y., 2016. Assessing a Temporal Change Strategy for Sub-Pixel Land Cover Change Mapping from Multi-Scale Remote Sensing Imagery. Remote Sens. 8:642. http://dx.doi.org/10.3390/rs8080642.

Ling, F., Li, W.B., Du, Y., \& Li, X.D., 2011. Land Cover Change Mapping at the Subpixel Scale With Different Spatial-Resolution Remotely Sensed Imagery. IEEE Geosci. Remote Sens. Lett. 8:182186. http://dx.doi.org/10.1109/Lgrs.2010.2055034.

Ling, F., Li, X.D., Xiao, F., \& Du, Y., 2014. Superresolution Land Cover Mapping Using Spatial Regularization. IEEE Trans. Geosci. Remote Sens. 52:4424-4439. http://dx.doi.org/10.1109/TGRS.2013.2281992.

Maghsoudi, Y., Collins, M.J., \& Leckie, D.G., 2013. Radarsat-2 Polarimetric SAR Data for Boreal Forest Classification Using SVM and a Wrapper Feature Selector. IEEE J. Sel. Top. Appl. Earth Observ. Remote Sens. 6:1531-1538. http://dx.doi.org/10.1109/Jstars.2013.2259219.

Mertens, K.C., De Baets, B., Verbeke, L.P.C., \& De Wulf, R.R., 2006. A sub-pixel mapping algorithm based on sub-pixel/pixel spatial attraction models. Int. J. Remote Sens. 27:3293-3310. http://dx.doi.org/10.1080/01431160500497127.

Montesano, P.M., Nelson, R., Sun, G., Margolis, H., Kerber, A., \& Ranson, K.J., 2009. MODIS tree cover 
validation for the circumpolar taiga-tundra transition zone. Remote Sens. Environ. 113:2130-2141. http://dx.doi.org/10.1016/j.rse.2009.05.021.

Morton, D.C., DeFries, R.S., Shimabukuro, Y.E., Anderson, L.O., Espirito-Santo, F.D.B., Hansen, M., et al., 2005. Rapid assessment of annual deforestaion in the Brazilian Amazon using MODIS data. Earth Interact. 9:1-22. http://dx.doi.org/10.1175/EI139.1.

Motohka, T., Shimada, M., Uryu, Y., \& Setiabudi, B., 2014. Using time series PALSAR gamma nought mosaics for automatic detection of tropical deforestation: A test study in Riau, Indonesia. Remote Sens. Environ. 155:79-88. http://dx.doi.org/10.1016/j.rse.2014.04.012.

Muad, A.M., \& Foody, G.M., 2012. Impact of Land Cover Patch Size on the Accuracy of Patch Area Representation in HNN-Based Super Resolution Mapping. IEEE J. Sel. Top. Appl. Earth Observ. Remote Sens. 5:1418-1427. http://dx.doi.org/10.1109/JSTARS.2012.2191145.

Nguyen, T.H., Jones, S.D., Soto-Berelov, M., Haywood, A., \& Hislop, S., 2018. A spatial and temporal analysis of forest dynamics using Landsat time-series. Remote Sens. Environ. 217:461-475. http://dx.doi.org/10.1016/j.rse.2018.08.028.

Olson, D.M., Dinerstein, E., Wikramanayake, E.D., Burgess, N.D., Powell, G.V.N., Underwood, E.C., et al., 2001. Terrestrial ecoregions of the worlds: A new map of life on Earth. Bioscience 51:933-938. http://dx.doi.org/10.1641/0006-3568(2001)051[0933:TEOTWA]2.0.CO;2.

Pan, Y., Birdsey, R.A., Fang, J., Houghton, R., Kauppi, P.E., Kurz, W.A., et al., 2011. A Large and Persistent Carbon Sink in the World's Forests. Science 333: 988-993. http://dx.doi.org/10.1126/science.1201609.

Pekkarinen, A., Reithmaier, L., \& Strobl, P., 2009. Pan-European forest/non-forest mapping with Landsat ETM plus and CORINE Land Cover 2000 data. ISPRS-J. Photogramm. Remote Sens. 64:171-183. http://dx.doi.org/10.1016/j.isprsjprs.2008.09.004.

Platnick, S., King, M.D., Ackerman, S.A., Menzel, W.P., Baum, B.A., Riedi, J.C., et al., 2003. The MODIS cloud products: algorithms and examples from Terra. IEEE Trans. Geosci. Remote Sens. 41:459-473. http://dx.doi.org/10.1109/TGRS.2002.808301.

Poorter, L., Bongers, F., Aide, T.M., Almeyda Zambrano, A.M., Balvanera, P., Becknell, J.M., et al., 2016. Biomass resilience of Neotropical secondary forests. Nature 530:211. http://dx.doi.org/10.1038/nature16512.

Qin, Y.W., Xiao, X.M., Dong, J.W., Zhang, G.L., Roy, P.S., Joshi, P.K., et al., 2016. Mapping forests in monsoon Asia with ALOS PALSAR 50-m mosaic images and MODIS imagery in 2010. Sci. Rep. 6:1-10. http://dx.doi.org/10.1038/srep20880.

Qin, Y.W., Xiao, X.M., Dong, J.W., Zhou, Y.T., Wang, J., Doughty, R.B., et al., 2017. Annual dynamics of forest areas in South America during 2007-2010 at 50-m spatial resolution. Remote Sens. Environ. 201:73-87. http://dx.doi.org/10.1016/j.rse.2017.09.005.

Rosenqvist, A., Shimada, M., Chapman, B., Freeman, A., De Grandi, G., Saatchi, S., et al., 2000. The Global Rain Forest Mapping project - a review. Int. J. Remote Sens. 21:1375-1387. http://dx.doi.org/10.1080/014311600210227.

Rosenqvist, A., Shimada, M., Ito, N., \& Watanabe, M., 2007. ALOS PALSAR: A Pathfinder mission for global-scale monitoring of the environment. IEEE Trans. Geosci. Remote Sens. 45:3307-3316. http://dx.doi.org/10.1109/TGRS.2007.901027.

Sexton, J.O., Noojipady, P., Song, X.P., Feng, M., Song, D.X., Kim, D.H., et al., 2016. Conservation policy and the measurement of forests. Nat. Clim. Change 6:192-196. http://dx.doi.org/10.1038/Nclimate2816. 
Sexton, J.O., Song, X.-P., Feng, M., Noojipady, P., Anand, A., Huang, C.Q., et al., 2013. Global, 30-m resolution continuous fields of tree cover: Landsat-based rescaling of MODIS vegetation continuous fields with lidar-based estimates of error. Int. J. Digit. Earth 6:427-448. http://dx.doi.org/10.1080/17538947.2013.786146.

Sheldon, S., Xiao, X., \& Biradar, C., 2012. Mapping evergreen forests in the Brazilian Amazon using MODIS and PALSAR 500-m mosaic imagery. ISPRS-J. Photogramm. Remote Sens. 74:34-40. http://dx.doi.org/10.1016/j.isprsjprs.2012.07.003.

Shimada, M., \& Isoguchi, O., 2002. JERS-1 SAR mosaics of Southeast Asia using calibrated path images. Int. J. Remote Sens. 23:1507-1526. http://dx.doi.org/10.1080/01431160110092678.

Shimada, M., Itoh, T., Motooka, T., Watanabe, M., Shiraishi, T., Thapa, R., et al., 2014. New global forest/non-forest maps from ALOS PALSAR data (2007-2010). Remote Sens. Environ. 155:13-31. http://dx.doi.org/10.1016/j.rse.2014.04.014.

Su, Y.F., Foody, G.M., Muad, A.M., \& Cheng, K.S., 2012. Combining Pixel Swapping and Contouring Methods to Enhance Super-Resolution Mapping. IEEE J. Sel. Top. Appl. Earth Observ. Remote Sens. 5:1428-1437. http://dx.doi.org/10.1109/JSTARS.2012.2216514.

Tateishi, R., Uriyangqai, B., Al-Bilbisi, H., Ghar, M.A., Tsend-Ayush, J., Kobayashi, T., et al., 2011. Production of global land cover data - GLCNMO. Int. J. Digit. Earth 4:22-49. http://dx.doi.org/10.1080/17538941003777521.

Tatem, A.J., Lewis, H.G., Atkinson, P.M., \& Nixon, M.S., 2002. Super-resolution land cover pattern prediction using a Hopfield neural network. Remote Sens. Environ. 79:1-14. http://dx.doi.org/10.1016/S0034-4257(01)00229-2.

Townshend, J.R., Masek, J.G., Huang, C.Q., Vermote, E.F., Gao, F., Channan, S., et al., 2012. Global characterization and monitoring of forest cover using Landsat data: opportunities and challenges. Int. J. Digit. Earth 5:373-397. http://dx.doi.org/10.1080/17538947.2012.713190.

Turner, D.P., Ritts, W.D., Cohen, W.B., Gower, S.T., Zhao, M., Running, S.W., et al., 2003. Scaling Gross Primary Production (GPP) over boreal and deciduous forest landscapes in support of MODIS GPP product validation. Remote Sens. Environ. 88:256-270. http://dx.doi.org/10.1016/j.rse.2003.06.005.

Walker, W.S., Stickler, C.M., Kellndorfer, J.M., Kirsch, K.M., \& Nepstad, D.C., 2010. Large-Area Classification and Mapping of Forest and Land Cover in the Brazilian Amazon: A Comparative Analysis of ALOS/PALSAR and Landsat Data Sources. IEEE J. Sel. Top. Appl. Earth Observ. Remote Sens. 3:594-604. http://dx.doi.org/10.1109/JSTARS.2010.2076398.

Wang, Q.M., Atkinson, P.M., \& Shi, W.Z., 2015. Fast Subpixel Mapping Algorithms for Subpixel Resolution Change Detection. IEEE Trans. Geosci. Remote Sens. 53:1692-1706. http://dx.doi.org/10.1109/Tgrs.2014.2346535.

Wang, Q.M., Shi, W.Z., \& Wang, L.G., 2014. Allocating Classes for Soft-Then-Hard Subpixel Mapping Algorithms in Units of Class. IEEE Trans. Geosci. Remote Sens. 52:2940-2959. http://dx.doi.org/10.1109/TGRS.2013.2267802.

Wardlow, B.D., \& Egbert, S.L., 2008. Large-area crop mapping using time-series MODIS 250 m NDVI data: An assessment for the U.S. Central Great Plains. Remote Sens. Environ. 112:1096-1116. http://dx.doi.org/10.1016/j.rse.2007.07.019.

Woodcock, C.E., Allen, R., Anderson, M., Belward, A., Bindschadler, R., Cohen, W., et al., 2008. Free access to Landsat imagery. Science 320:1011-1011. http://dx.doi.org/10.1126/science.320.5879.1011a.

Wu, K., Du, Q., Wang, Y., \& Yang, Y.T., 2017. Supervised Sub-Pixel Mapping for Change Detection 
from Remotely Sensed Images with Different Resolutions. Remote Sens. 9:284. http://dx.doi.org/10.3390/rs9030284.

Xiao, J.F., \& Moody, A., 2005. A comparison of methods for estimating fractional green vegetation cover within a desert-to-upland transition zone in central New Mexico, USA. Remote Sens. Environ. 98:237-250. http://dx.doi.org/10.1016/j.rse.2005.07.011.

Xu, Y., Lin, L., \& Meng, D.Y., 2017. Learning-Based Sub-Pixel Change Detection Using Coarse Resolution Satellite Imagery. Remote Sens. 9:709. http://dx.doi.org/10.3390/rs9070709.

Yu, Y.J., \& Acton, S.T., 2002. Speckle reducing anisotropic diffusion. IEEE Trans. Image Process. 11:1260-1270. http://dx.doi.org/10.1109/TIP.2002.804276.

Zhang, L.P., Zhang, L.F., \& Du, B., 2016. Deep Learning for Remote Sensing Data A technical tutorial on the state of the art. IEEE Geosci. Remote Sens. Mag. 4:22-40. http://dx.doi.org/10.1109/Mgrs.2016.2540798.

Zhang, Y.H., Atkinson, P.M., Li, X.D., Ling, F., Wang, Q.M., \& Du, Y., 2017a. Learning-Based SpatialTemporal Superresolution Mapping of Forest Cover With MODIS Images. IEEE Trans. Geosci. Remote Sens. 55:600-614. http://dx.doi.org/10.1109/TGRS.2016.2613140.

Zhang, Y.H., Foody, G.M., Ling, F., Li, X.D., Ge, Y., Du, Y., et al., 2018. Spatial-temporal fraction map fusion with multi-scale remotely sensed images. Remote Sens. Environ. 213:162-181. http://dx.doi.org/10.1016/j.rse.2018.05.010.

Zhang, Y.H., Li, X.D., Ling, F., Atkinson, P.M., Ge, Y., Shi, L.F., et al., 2017b. Updating Landsat-based forest cover maps with MODIS images using multiscale spectral-spatial-temporal superresolution mapping. Int. J. Appl. Earth Obs. 63:129-142. http://dx.doi.org/10.1016/j.jag.2017.07.017.

Zhong, Y.F., Wu, Y.Y., Xu, X., \& Zhang, L.P., 2015. An Adaptive Subpixel Mapping Method Based on MAP Model and Class Determination Strategy for Hyperspectral Remote Sensing Imagery. IEEE Trans. Geosci. Remote Sens. 53:1411-1426. http://dx.doi.org/10.1109/TGRS.2014.2340734. 